2014-06-30

\title{
Youth Motivation as a Predictor of Treatment Outcomes in a Community Mental Health System
}

\author{
Brett M. Merrill \\ Brigham Young University - Provo
}

Follow this and additional works at: https://scholarsarchive.byu.edu/etd

Part of the Psychology Commons

\section{BYU ScholarsArchive Citation}

Merrill, Brett M., "Youth Motivation as a Predictor of Treatment Outcomes in a Community Mental Health System" (2014). Theses and Dissertations. 4187.

https://scholarsarchive. byu.edu/etd/4187

This Dissertation is brought to you for free and open access by BYU ScholarsArchive. It has been accepted for inclusion in Theses and Dissertations by an authorized administrator of BYU ScholarsArchive. For more information, please contact scholarsarchive@byu.edu, ellen_amatangelo@byu.edu. 
Youth Motivation as a Predictor of Treatment

Outcomes in a Community

Mental Health System

Brett M. Merrill

A dissertation submitted to the faculty of

Brigham Young University

in partial fulfillment of the requirements for the degree of

Doctor of Philosophy

Jared S. Warren, Chair

Sam A. Hardy

Michael J. Lambert

Chad Jensen

Robert D. Ridge

Department of Psychology

Brigham Young University

July 2014

Copyright (C) 2014 Brett M. Merrill

All Rights Reserved 


\author{
ABSTRACT \\ Youth Motivation as a Predictor of Treatment \\ Outcomes in a Community \\ Mental Health System \\ Brett M. Merrill \\ Department of Psychology, BYU \\ Doctor of Philosophy
}

The role of motivation in relation to youth symptoms and psychotherapy outcomes is not well understood. Some cross-sectional research suggests that motivation predicts youth treatment outcome in low-motivation populations. The purpose of this study was to examine patterns of change in youth motivation over the course of treatment and to elucidate the relation between motivation, youth symptoms, and psychotherapy outcomes in a routine community mental health setting. Participants and their caregivers were from three community mental health outpatient clinics and completed youth or parent forms of the Youth Outcome Questionnaire (Y-OQ) and Treatment Support Measure (TSM) at frequent intervals throughout treatment. Data were collected over a period of about 2 years. On average, youth motivation significantly increased over the course of therapy according to self- $(p<.001)$ and parent-report $(p<.001)$. This change followed a square root function better than linear and quadratic models. Initial motivation was not predictive of overall change in symptoms or rate of change at the $p<.05$ level after accounting for initial levels of youth symptoms. Individual rates of change for youth motivation varied significantly over the course of treatment $(p<.001)$, which might suggest unique trajectories of motivation for different subsets of youth based on presenting concerns or other variables.

Keywords: psychotherapy, psychotherapy research, adolescent, youth, motivation, outcome 


\section{ACKNOWLEDGEMENTS}

"Yea, I know that I am nothing; as to my strength I am weak; therefore I will not boast of myself, but I will boast of my God, for in his strength I can do all things.” Alma 26:12

In recognizing those who have supported me along this arduous path, I first want to acknowledge my Eternal Father. The peace I receive in my life as a result of following his ways is unsurmountable, and the family he has granted me brings me daily joy. My wife, Collette, also deserves much of the credit for this work. She has endlessly supported me through the long days/nights and encouraged me to finish promptly. I hope that I can equally support and encourage her when she pursues her dreams of furthering her education. I wish for our children to emulate our love for education and pursue their dreams.

I am indebted to my chair, Jared Warren, for his initiation of this project, calming optimism, and example of a strong professor and gentle father. And, of course, for the many hours of laughter that came from his introverted humor. Additional thanks to Sam Hardy, Mike Lambert, Chad Jensen, and Bob Ridge for finding a most inauspicious day and time to meet together and for gently leading me in (and out) of convoluted quandaries. A special thanks to Chongming Yang for his positive attitude in the face of perplexing statistical challenges.

Finally, I want to thank my parents. Without my mother's passion for education and determined example, I likely would not have pushed this far. Dad...I hope you're proud. Love. 


\section{TABLE OF CONTENTS}

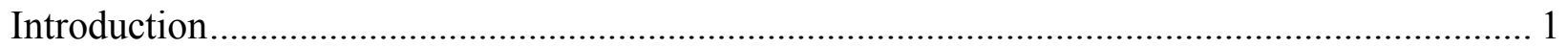

Youth Psychotherapy Outcome Research..................................................................... 4

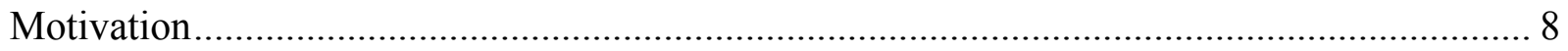

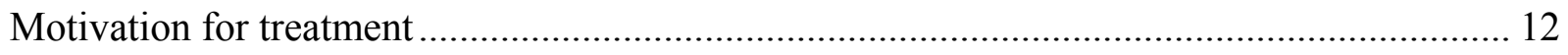

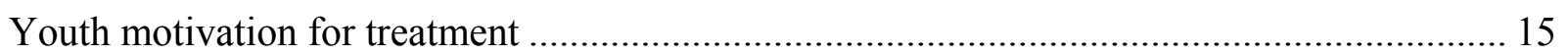

Limitations of previous research.............................................................................. 18

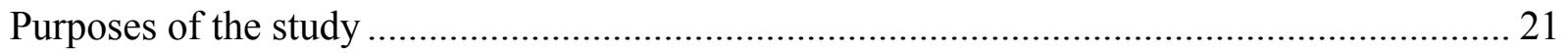

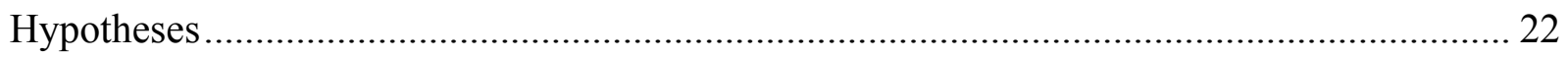

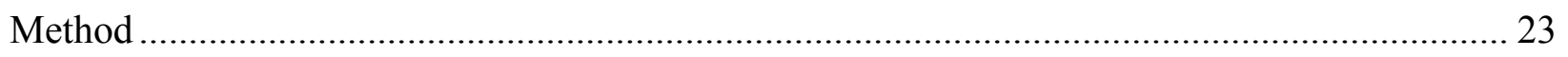

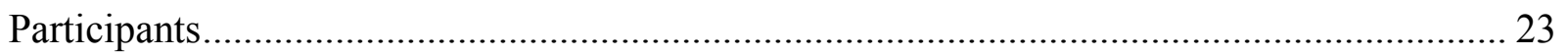

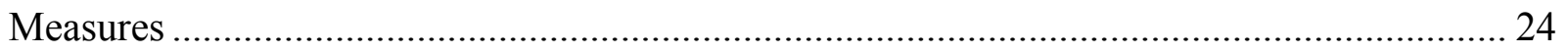

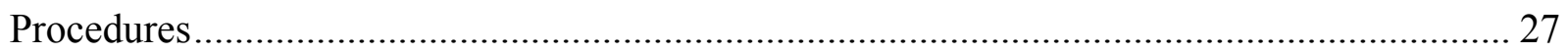

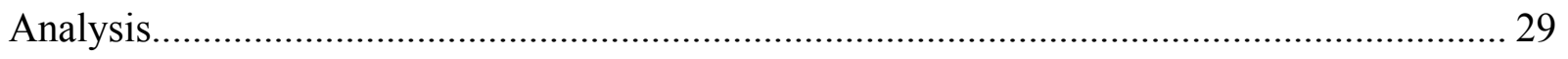

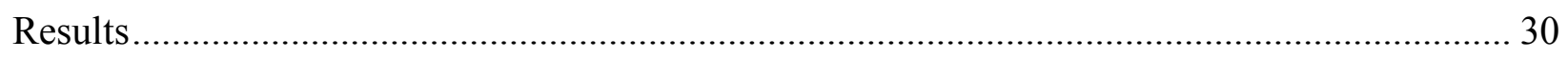

Hypothesis 1: Youth Motivation Trajectories................................................................. 31

Hypothesis 2: Initial Motivation and Intake Symptoms ................................................ 33

Hypothesis 3: Initial Youth Motivation Predicting Overall Symptom Reduction................... 34

Hypothesis 4: Initial Youth Motivation Predicting Rate of Change.................................... 35

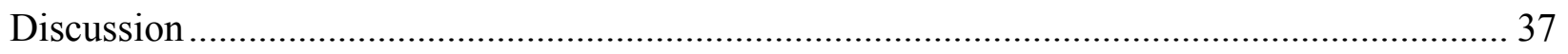




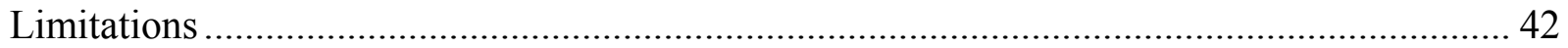

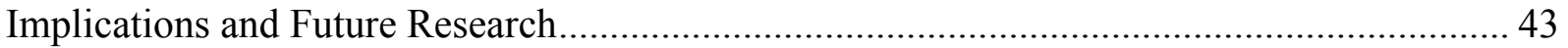

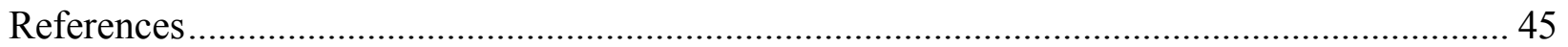

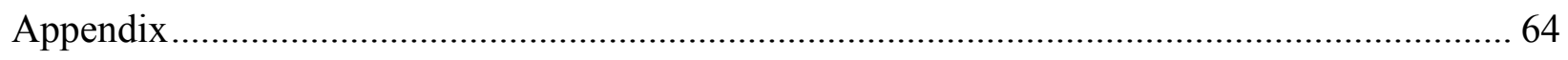




\section{TABLES}

Table 1. Comparison of Selected Features in Clinical Trials vs. Clinical Practice ....................... 2

Table 2. Unstandardized Mean Intercepts and Slopes of Y-OQ and TSM-YM....................... 34

Table 3. Intake and Change Means and Standard Deviations of Y-OQ, TSM-YM, and CBCL .. 34 


\section{FIGURES}

Figure 1. Self-Determination Theory .............................................................................. 9

Figure 2. Average Youth Motivation Change Trajectory …................................................. 32

Figure 3. A Randomized Sample of Individual Motivation Trajectories ................................ 36

Figure 4. Average Youth and Parent-Reported Symptom Change Trajectories......................... 37 
Youth Motivation as a Predictor of Treatment Outcomes in a Community Mental Health System

Psychopathology varies by disorder, age, sex, socioeconomic status (SES), ethnicity, and geographical location, among other factors (Alegría et al., 2008), and the effects of mental illness on youth are wide-spread and potentially devastating. Unfortunately, due to costs, clinician availability, geographical location, and a variety of other reasons, many children requiring care to attenuate mental health symptoms do not receive the services they need (Kazdin \& Blase, 2011). For those few youth who do receive services, there is some promise. More than 1,500 treatment outcome studies, including over 500 methods of treatment, provide strong evidence that psychotherapy in youth is an effective way of managing mental health symptoms (Kazdin, 2003; Kazdin \& Wassel, 2000; Nathan, 2002). Unfortunately, most of the extant studies include methodological flaws (Weisz, Jensen, \& McLeod, 2005) and lack the rigor of empirical and quantitative outcome measurements (Kazdin, 2004).

While psychotherapy has been proven to be beneficial, not everyone improves at the same rate or even experiences alleviation of symptoms. In fact, some people might actually experience a worsening of symptoms over the course of therapy. Lambert and Ogles (2004) suggest deterioration rates in adults have been estimated at approximately $5-10 \%$. However, youth receiving mental health services in some community settings are estimated to have deterioration rates as high as $24 \%$ (Warren, Nelson, Mondragon, Baldwin, \& Burlingame, 2010). This staggering number warrants immediate attention in both the settings of psychotherapy and the mechanisms of action that prove to be beneficial (or detrimental) in psychotherapy, as the potential causes for this finding are largely unknown (Weisz, Weiss, \& Donenberg, 1992; Weisz, Weiss, Han, Granger, \& Morton, 1995). 
The lack of research studies with adequate generalizability to usual care settings is a serious deficiency in the youth psychotherapy literature (Garland, Hurlburt \& Hawley, 2006; Kazdin, 2003; Weersing \& Weisz, 2002; Weisz et al., 2005). Those willing to participate in efficacy trials (clinical trials) could exhibit significant differences from those who engage in effectiveness research (see Table 1; Burlingame, Wells, Lambert, Cox, \& Maruish, 2004; Kazdin, 1991; Weisz, Jensen, \& McLeod, 2005), suggesting a gap between research findings from laboratory settings and its application to usual care settings. This chasm increases as researchers continue to conduct studies in tightly controlled environments that are not representative of actual practice settings, leading many professionals to ignore potentially useful evidence-based practices (Burlingame et al., 2004; Kazdin, 1991).

\section{Table 1}

Comparison of Selected Features in Clinical Trials vs. Clinical Practice

\begin{tabular}{|ll|}
\hline Clinical Trials & Clinical Practice \\
\hline Cases usually recruited for treatment & Cases usually referred for treatment \\
Cases usually seen in schools & Cases usually seen in clinics or private practice settings \\
Treatment duration averages 8-10 weeks & Treatment duration averages 6-12 months \\
Treatment usually provided in groups & Treatment usually provided individually \\
Parents infrequently involved in treatment & Parents usually involved in treatment \\
Family infrequently seen in treatment & Family often seen as a unit \\
Psychodynamic, psychoanalytically oriented, & Psychodynamic, psychoanalytically oriented, family, and \\
family, and eclectic approaches rarely studied & eclectic approaches often used \\
Often screen out potential confounding comorbid & Majority of cases involve comorbidity \\
disorders & \\
\hline
\end{tabular}

In addition to setting, the paucity of research examining underlying mechanisms of action leading to positive psychotherapy in youth is a prominent deficiency in the literature (Kazdin, 2003, 2004, 2006, 2009; Weersing \& Weisz, 2002; Weisz \& Kazdin, 2003). It is well accepted 
that psychotherapy works to reduce youth symptoms, but little is known about what mechanisms are responsible for symptom reduction (Kazdin, 2009). Further understanding of mechanisms of change in "real life" settings (i.e., traditional clinic settings) has implications for optimizing implementation of psychotherapy services. That is to say, clinicians may have an increased ability to maximize factors known to lead to improved outcomes while minimizing factors known to lead to negative outcomes.

Some research has been established that begins to identify potential mechanisms of change. In fact, evidence suggests that youth who do not attend therapy sessions consistently, do not participate wholeheartedly in the therapeutic process, or do not complete treatment show less improvement than those who actively participate in therapy, steadily attend sessions, and do not discontinue treatment prematurely (Ansari, Gouthro, Ahmad, \& Steele, 1996; Kazdin, Mazurick, \& Seigel, 1994). These factors appear to be moderating the degree of improvement observed in treatment outcomes that share a common element: motivation. Motivation, particularly motivation that exists within an individual regardless of external forces (intrinsic motivation), has been shown to predict engagement in therapy, and be a more significant predictor of outcome than socio-demographic and other background variables (Joe, Simpson, \& Broome, 1998). Indeed, some research even suggests motivation is a stronger predictor of outcome (using symptom reduction and remission as criteria) than the therapeutic alliance (Zuroff, et al., 2007), a well-understood predictor of outcome. This finding provides strong evidence for the evaluation of motivations impact on treatment outcomes.

The majority of studies examining the impact of motivation on treatment outcomes have concentrated on adult, low-motivation populations (e.g., substance abuse, eating disorders, inpatient settings; Sutton, 2001). Very few studies have examined motivation in youth 
populations, and even fewer studies have researched the potential impact of youth motivation in usual care settings. Additionally, little is known about the changes in trajectories motivation might have throughout the therapy process. While pre-treatment motivation has been indicated as a predictor of change (Melnick, De Leon, Hawke, Jainchill, \& Kressel, 1997; Rodriguez-Cano \& Beato-Fernandez, 2005; Rieger et al., 2000), it is plausible to expect motivation to wax and wane throughout the course of therapy rather than remain constant with pre-treatment levels, which may impact treatment outcomes in a nonlinear fashion. The purpose of the present study is to evaluate youth motivation as a potential predictor (moderator) of treatment outcomes in a naturalistic setting (e.g. community outpatient) for children and adolescents. Moreover, exploring how motivation might change throughout the course of therapy is a particularly important addition to understanding how motivation might impact treatment outcomes.

\section{Youth Psychotherapy Outcome Research}

The number of children and adolescents requiring psychological care has substantially increased in the last few years (Appleyard, Egeland \& Sroufe, 2007). Lifetime prevalence rates of psychopathology are estimated at 14-22\% for all children and adolescents (Kazdin, 2003, 2004; Mash \& Dozois, 2003). Given the current population of the United States, this percentage equates to approximately 14 million youth who experience emotional or behavioral problems that cause significant impairment. This prodigious number of youth experiencing psychological challenges does not include those children and adolescents who may be experiencing significant distress from psychological challenges that are considered sub-threshold, or those not meeting full criteria to qualify for a diagnosis. This "at-risk" population of youth likely suffers a great deal from social, emotional, and psychological impairment (Kazdin, 2003, 2004). In addition, those that meet threshold requirements for a formal diagnosis often experience multiple types of 
challenges concurrently. Disorder comorbidity rates among children and adolescents are estimated to range from 50\% to greater than 70\% (Angold, Costello, Erkanli, 1999; Kazdin, 2004). Meeting the needs of these youth is a vast concern that requires empirical interventions proven to be effective in the relief of symptoms for children and adolescents (Levant \& Hasan, 2008).

Establishment of effective psychotherapeutic interventions has been a slow and arduous progression. Over $40 \%$ of the 1,500 treatment outcome studies for children and adolescents were conducted after 1990 (Kazdin, 2003). Over 500 psychotherapies have been used in the treatment of youth with psychological disorders (Kazdin, 2007). Evidence-based treatments have been established for use in multiple child and adolescent disorders: depression, anxiety, obsessive compulsive disorder, oppositional defiant and conduct disorders, and autistic disorder (Kazdin \& Nock, 2003; McClellan \& Werry, 2003).

With the recent surge of research providing evidence for the effectiveness of psychotherapy in symptom reduction, there has been a shift from determining "if" psychotherapy works to "how well" psychotherapy works in children and adolescents. In a review of metaanalyses by Weisz, Jensen and Hawley (2006), the authors compared children who received psychotherapy to those who did not (control groups). They concluded, along with other researchers, that youth who participate in therapy are better off than those who do not receive treatment (Kazdin, 2003; Kazdin \& Nock 2003; Weisz et al. 2005; Weisz \& Kazdin, 2003), with reported effect sizes ranging from .71 to .84 .

The burgeoning accumulation of child and adolescent psychotherapy studies, while encouraging, mostly lend support to the efficacy (how well a treatment works in laboratory settings, or clinical trials) of psychotherapy rather than the effectiveness (how well a treatment 
works in actual practice) of psychotherapy (Lutz, 2003). In fact, there is a paucity of research in "real-world" settings where most children and adolescents participate in treatment (Garland et al., 2005; Kazdin, 2004; Warren, et al., 2010; Weersing \& Weisz, 2002; Weisz \& Kazdin, 2003). Thus, most youth treatment outcome research does not strongly support effectiveness in usual care settings. Instead, it is more applicable to atypical youth lacking comorbid diagnoses, medical complications, language barriers, and other "real" factors often not accounted for in controlled, laboratory settings (Weisz, Jensen-Doss \& Hawley, 2006). Conversely, inclusion of these "messy" factors is thought to be representative of most treatment-seeking clients. For example, usual care settings are thought to comprise more clinically severe cases and more comorbid cases, with comorbidity rates ranging from $50-70 \%$, than these "too perfect" laboratory settings (Kazdin, 2004; Weisz, Jensen-Doss \& Hawley, 2006; Warren, et al., 2010).

The few extant studies examining treatment effectiveness in usual care settings lead to disheartening results, with near zero treatment effect sizes (Weisz, Weiss, \& Donenberg, 1992; Weisz, Weiss, Han, Granger, \& Morton, 1995). Additionally, attrition rates in traditional community settings are unexpectedly high, with estimates ranging between $28 \%$ and $85 \%$ (Garcia \& Weisz, 2002; Pina, Silverman, Weems, Kurtines, \& Goldman, 2003), suggesting many youth that require therapeutic services are not improving due to incomplete treatment. Even more concerning are the rates of children and adolescents that display significantly worse symptoms after participating in usual care psychotherapy (Boswell, Castonguay, \&Wasserman, 2010; Lilienfeld, 2007; Warren et al., 2010). In fact, these estimates suggest as many as $24 \%$ of children and adolescents receiving services in some public community mental health settings and approximately $14 \%$ of youth in private managed care settings may deteriorate while receiving therapy (Warren et al., 2010). 
Identifying elements of practice that might differ between research settings and traditional clinical settings will likely improve the utility of evidence-based practice and narrow the gap between these two areas (Garland et al., 2005). Kazdin (2007) proposed some factors that might explain potential differences between these settings (see Table 1). In addition, features such as recruitment of participants, individual differences among therapists, level of supervision, caseload, and SES might also contribute to these dissimilarities (Kazdin, 2009). Understanding the complexity of psychotherapy and the processes and mechanisms that contribute to effective therapy outcomes is a crucial step in modifying elements that are ineffective and implementing effective practices in their stead (Kazdin, 2006). These elements are often referred to as mechanisms of action, or mechanisms of change.

Mechanisms of action refer to the "how" or "why" change occurs and includes both mediators and moderators (Kazdin, 2003). Mediators are defined as intervening variables that may statistically account for the relationship between therapeutic interventions and treatment outcome; they may explain how external events predict internal psychological significance. For example, an intervention may lead to better treatment outcomes, but it is because the intervention led to a change in familial relationships, and it is this relationship change that led to better treatment outcomes. Without this mediating change in familial relationships, the intervention would not have been effective. Moderators, on the other hand, are defined as characteristics that impact the direction or strength of the relationship between psychotherapeutic intervention and treatment outcome (Kazdin, 2007). In the previous example, suppose the therapeutic intervention is only successful with males. Gender would then be considered a moderator, because it alters the strength of the relationship between intervention and outcome. Both mediators and moderators are thought to be responsible for changes that occur in mental health 
services. Identification of mediators and moderators that effect successful treatment outcomes is an essential step in improving psychotherapy techniques and increasing efficiency in mental health services. There is some evidence to support motivation as a potential moderator of treatment outcome in both adult and youth (Aharonovich, Amrhein, Bisaga, Nunes, \& Hasin, 2008; Amrhein, Miller, Yahne, Palmer, \& Fulcher, 2003; DiClimente, Bellino, \& Neavins, 1999;

Hettema, Steele, \& Miller, 2005; Madson \& Campbell, 2006); however, this construct has received relatively little attention in community-based youth mental health services.

\section{Motivation}

Within the realm of psychology the term motivation varies in its definition and level of clarity and precision (Holt, 1967; Rosenbaum \& Horowitz, 1983). In attempting to semantically define motivation, subfields in psychology have proposed varying theories to explain this broad concept. Theoretical explanations include elements of intrinsic versus extrinsic influences (Deci \& Ryan, 1985), incentive-driven behaviors (Killeen, 1985), drive-reduction (Hull, 1943), and cognitive dissonance (Festinger, 1957) to describe what motivates beings to action.

The most commonly agreed upon and consistent element of motivation involves intrinsic and extrinsic influences on behavior. Intrinsic motivation refers to motivation that exists within an individual and is not necessarily influenced by external pressures (e.g., money or grades). Extrinsic motivation, on the other hand, refers to motivation that is externally driven, or from sources outside of the individual, such as praise or fear of punishment. Both intrinsic and extrinsic motivation have been studied by educational and social psychologists since the 1970s, with more recent research by Deci and Ryan (1985) and Bandura (1997), yet concrete definitions of motivation are still lacking and often contended (Reiss, 2004). 
Deci and Ryan's (1987) work eventually emerged into a generally accepted theory: SelfDetermination Theory (SDT). This proposed theoretical system assumes human beings are innately drawn toward intrinsic motivation and suggest this is done via self-exploration rather than through external pressures (Deci \& Ryan, 1991). SDT enhances definitions of motivation by conceptualizing motivation as a continuum ranging from Amotivation to Intrinsic Motivation, with Intrinsic Motivation assumed to be inherently more desirable, or self-determined (see Figure 1). Along this continuum, levels of motivation are partitioned by controlled (dependent on external rewards) and autonomous (independent of external rewards) reasons.

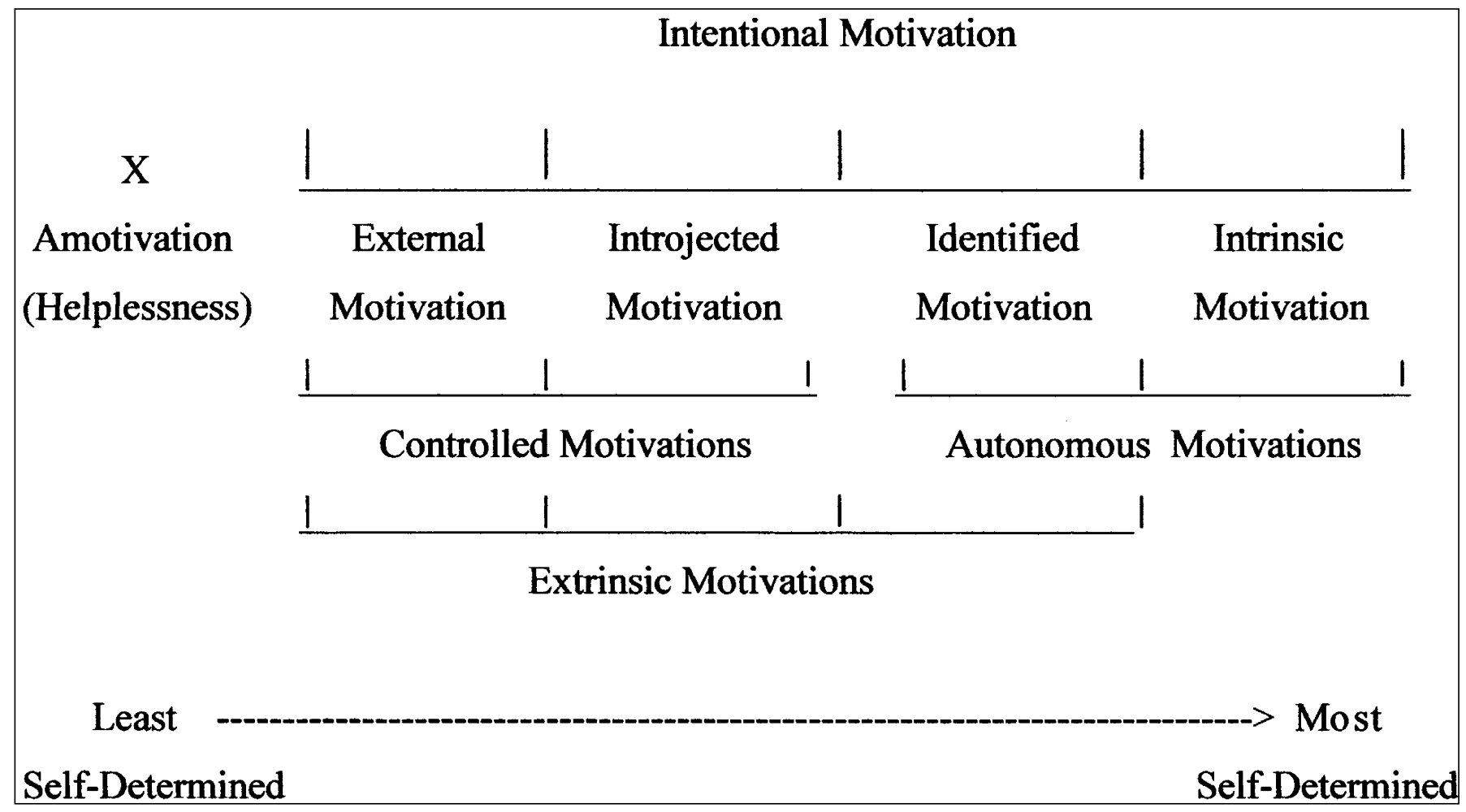

Figure 1. Self-Determination Theory. Logical progression from Amotivation to Intrinsic Motivation (Ryan \& Deci, 2000).

The continuum of motivation SDT describes has direct implications in explaining why a person might seek therapy, why someone would remain engaged in services, and why some individuals experience better, or worse, outcomes than other individuals. An extensive study by Abblett (2002) linked self-determined theoretical conceptualizations of motivation with 
psychotherapy applications of motivation. Intrinsic vs. extrinsic motivation was found to significantly predict treatment service utilization (i.e., participation, adherence, and attrition) with correlations between .1 and .3. Moreover, participants deemed to be more internally motivated were more likely to remain engaged in the therapy process while more externally motivated individuals (or less autonomous individuals) were more likely to exhibit greater estrangement from the change process and have poorer outcomes. There is much research to support SDT as a theoretically sound model (Deci \& Ryan, 1985; Ryan \& Deci, 2000, 2008); however, very little research supports the robustness of this model in actual practice (Ryan \& Deci, 2000).

In an attempt to relate motivation theories to therapy settings and standardize common components of motivation across theory, Prochaska and DiClimente (1982) developed a model to explain the process toward a genuine willingness of patients to make changes in their behavior, which they termed the Transtheoretical Model (TTM), or the "Stages of Change Model". Like SDT, TTM further elucidates a working definition of motivation (Hettema, Steele, \& Miller, 2005). Initially viewed as mutually exclusive from SDT, TTM provides hands-on groundwork for understanding motivation, particularly in therapy settings.

The model consists of five "Stages of Change" representative of an individual's readiness to change and range from Precontemplation to Maintenance. Precontemplation includes individuals who do not understand their behaviors as problematic or are under-informed about the consequences of their actions. Colloquially, this stage describes those that are "in denial" or "resistant" to their problems (Prochaska \& DiClimente, 2005). Maintenance, on the other hand, is considered a continuation of change after more concrete and direct actions to accomplish their goals have been completed. During this stage, individuals successfully avoid former undesirable 
behaviors and effectively demonstrate new alternatives. This model of motivation is easily understood in therapeutic contexts as it appears to capture an essence of readiness to change. Indeed, it is thought to be especially applicable to individuals suffering from addictions or other problems where relapses are considered common occurrences, but it has not been applied to more general populations or problems.

The Stages of Change model provides empirically sound evidence for describing the change process; however, it lacks support explicating why it works as a psychotherapy tool. Conversely, SDT is theoretically sound, yet is missing strong empirical evidence in real-world settings. Both are thought to contribute to the delineation of motivation, but little work has been done to integrate descriptions of motivation into a cogent and pragmatic definition (Abblett, 2002).

One endeavor to transfer these theoretical models into practical applications is by a recently developed tool designed to increase motivation of clients in therapy settings: Motivational Interviewing (MI; Miller \& Rollnick, 2002). MI is a client-centered technique that promotes movement toward intrinsic motivation using semi-directive methods of exploring ambivalence. Applications of MI are most often seen in low-motivation populations (e.g., substance abuse; eating disorders; chronic illness) and include the basic goals of expressing empathy for the client, developing discrepancies in ambivalence, rolling with resistance, and eliciting "change talk." MI has become a widely adopted system of promoting change by increasing motivation in clients. However, attempts to link MI with a coherent nomological network have been largely absent in the literature. Consequently, some research (Markland, Ryan, Tobin \& Rollnick, 2005; Vansteenkiste, \& Sheldon, 2006) has proposed a connection between SDT and MI, which allows for greater description of intrinsic vs. extrinsic factors of 
motivation as it relates to treatment. This connection is based on the assumption that people have an inborn tendency toward personal progression and psychological integration; MI appears to provide the environmental and social components necessary to support this tendency. In other words, MI is supportive of change considering its conduciveness to promote autonomy and control of oneself.

\section{Motivation for Treatment}

Definitions of motivation instill a slightly different essence when applied in treatment settings. In psychotherapy, motivation is thought to be less of an emotional drive and more of an actionable term. Therefore, for the purposes of this study, motivation is defined as the willingness of patients to demonstrate any change which leads to improvement in their functioning (i.e., reduction and/or elimination of symptoms/criteria indicative of mental disorders) and perform the actions necessary to achieve such changes.

Given the conceptual foundation provided by empirical evidence (SDT; TTM; MI) demonstrating the relationship between motivation and behavioral change, it is probable that motivation to change likewise impacts treatment outcomes. A few studies (Abblett, 2002; Brogan, Prochaska, \& Prochaska, 1999) suggest that individuals who identify themselves in a precontemplation state were much more likely to prematurely cease services. Those who did not highly endorse precontemplative attitudes, however, were associated with appropriate termination schedules or continuing therapy until adequate changes had been made. It stands to reason that those with low motivation would not realize a need to remain in therapy if they do not currently view their behaviors as problematic. Consequently, Abblett further asserted that those who were a step above Precontemplation, and willing to consider changes were more likely to utilize services due to their willingness to introduce improvements into their lives. 
Further, individuals that identified themselves as having greater amounts of autonomous selfregulation (intrinsic motivation) were more likely to be actively engaged in the change process, while those who were more externally motivated demonstrated greater estrangement from the change process.

In a literature review, Ryan and Deci (2000) attributed a list of reasons persons might be more prone to perceive circumstances as caused by external forces, thus limiting their internal locus of control: threats, deadlines, pressured evaluations, and imposed goals. These factors, common in most workplaces and academic settings, may reduce internal motivation to change by attenuating security and relatedness within individuals. These impositions on internal motivation could account for reasons the therapeutic alliance works to promote positive outcomes; increases in relatedness and security may lead to rises in internal locus of control and motivation to change.

Eight years later, Ryan and Deci (2008) conducted another review of the literature to further explicate the impact of motivation in treatment. They postulated that the framework of SDT explains why MI might work in therapy settings. Eliciting speech regarding change from the client encourages them to make decisions on their own, which increases levels of autonomy for the client. That is to say clients are more likely to achieve positive outcomes in therapy when they learn to take control over their own decisions and integrate learning and behavior change on a personal level—adding more supportive evidence for combining TTM principles on an intrinsic/extrinsic scale of motivation.

There appears to be a general consensus that intrinsic motivation is the most desirable level of motivation as it tends to lead to better treatment outcomes. DiClimente, Bellino, and Neavins (1999), however, argue that external threats (e.g., job loss, social influences) are also 
significant predictors of positive outcomes. While confrontational styles of therapy may not be the most powerful, external influences also reduce client symptoms. In fact, they provide evidence that motivation (both internal and external) predicts outcomes post-treatment and at three years follow up.

In a meta-analysis of 72 clinical trials, the impact motivation enhancement therapy (a nonconfrontational approach that utilizes principles and strategies of MI along with problem feedback as a form of treatment) may have on treatment outcomes was evaluated (Hettema, Steele, \& Miller, 2005). The study consisted of 14,267 clients ranging from 16 to 62 years of age. An average short-term, between group effect size for therapy designed to increase motivation in therapy (MI) was estimated at .77. However, the magnitude of this effect decreased over time with an estimated .30 effect size at one-year follow up. This conglomeration of effect sizes elucidates the general impact of motivation on treatment services, but it lacks precision due to lack of standardization among treatment adherence, differences in population (age, SES, ethnicity, target problems), and outcome measures used to track change. As a whole, however, motivation appears to influence treatment outcomes, though its effects may diminish post-treatment.

Not all trials of motivation enhancement, whether introduced separately or included in regular treatment, have been positive. Non-significant findings for the impact of motivation in treatment have been reported with eating disorders (Treasure et al., 1998), drug abuse and dependence (Miller, Yahne \& Tonigan, 2003; Winhusen et al., 2008), smoking cessation (Baker et al., 2006; Colby et al., 1998), and problem drinking (Kuchipudi, Hobein, Fleckinger, \& Iber, 1990). These findings may reflect accurate appraisals of the influence of motivation in 
treatment, or they may be more representative of Type II errors attributable to weak designs or other methodological flaws.

More reliable coding systems are in the development stage which may more thoroughly address these potential threats to validity (Madson \& Campbell, 2006). Currently, the majority of studies indicate institution of motivation enhancement strategies in treatment positively impact outcomes, particularly those that encourage clients to elicit change talk and increase autonomy and internal motivation (Aharonovich, et al., 2008; Amrhein, et al., 2003). Furthermore, when MI is added to other active treatment procedures, the treatment effects appear to be amplified (Miller \& Rose, 2009). This finding is counterintuitive, as most additive treatment effects are reduced when combined with an additional method. Thus, MI appears to be a powerful tool that can be added to already existing treatment manuals or procedures. In addition, it lends support to clinicians to alter therapy if expected outcome trajectories are violated (Britton \& Williams, 2008). This is especially applicable to populations that experience a high degree of ambivalence (i.e. suicide, addiction, eating disorders), but it may be ineffective, or even counter-productive, to use motivational enhancement techniques with individuals who are following expected outcome trajectories and may already be motivated to change (Ondersma et al., 2009). However, moderators that influence the strength or direction of outcomes have yet to be clearly defined (Kazdin, 2006).

\section{Youth Motivation for Treatment}

The number of studies investigating treatment outcome in youth is generally increasing, yet very few studies have been designed to examine youth motivation in relation to treatment outcomes. There is some literature suggesting motivation enhancement as a key component in treating adolescent, low motivation populations (Lambie \& Sias, 2006). A few studies exist that 
explore youth motivation in personality disorders (Sainsbury, Krishnan \& Evans, 2004), mood disorders (Fowles, 1994), obsessive compulsive disorder (Pinto, Pinto, Neziroglu, \& YaryuraTobias, 2007), pathological gambling (Wulfert, Blanchard \& Martell, 2003), obesity (Prochaska, Norcross, Fowler, Follick \& Abrams, 1992), smoking cessation (DiClimente, et al., 1991), alcohol abuse (Rollnick, Heather, Gold \& Hall, 1992), eating disorders (Wilson \& Schlam, 2004), and substance use disorders (Miller \& Rollnick, 2002). However, results comparing adult motivation to youth motivation for treatment are mixed.

Some argue few differences exist between adult and adolescent levels of motivation for change (Geller et al., 2008; Perkins et al., 2007). However, others conclude adolescents tend to exhibit less motivation than adults due to developmental differences between the two age ranges, because adolescents are more likely to be extrinsically motivated than adults (Breda \& Heflinger, 2007). These developmental differences suggest increase in age leads to subsequent increase in levels of motivation, with more emphases placed on internal motivation (Jainchill, Bhattacharya, \& Yagelka, 1995; Rumpold, et al., 2005). Despite these conceivable differences between age groups, Melnick, De Leon, Hawke, Jainchill, and Kressel (1997) found pre-treatment motivation significantly predicted treatment retention in both adult and youth populations. In addition to retention, motivation has also been shown to predict other factors (i.e., hospital admission and self-monitoring) related to treatment outcome in adolescent populations (Ametller, Castro, Serrano, Martinez, \& Toro, 2005; Gusella, Butler, Nichols, \& Bird, 2003), which may be better indicators of treatment outcome in youth since treatment retention could be strongly dependent on parental decision.

Many disorders begin in childhood and continue on to adulthood (Kazdin, 2003). Thus, studying child and adolescent populations and establishing preventative interventions before 
problems exacerbate seems sensible. Substance use is one area where focus on adolescents is particularly important (Lennox \& Cecchini, 2008). An early study by Krug and Henry (1974) suggested those who use illicit drugs, particularly child and adolescent drug users, are more externally motivated and less internally motivated to change behaviors. More recently, Breda and Heflinger (2007) provided evidence that drug abusers are more motivated to change if they have reached "rock bottom," meaning an adolescent who feels his/ her life cannot become any worse is more likely to be motivated to improve his /her life circumstance. In fact, higher distress levels among these adolescents were associated with increases in motivation to reduce drug use. Likewise, results from a study by King, Chung, and Maisto (2009) indicated reductions in adolescent clients using marijuana was predicted by higher levels of motivation to abstain from marijuana more so than perceived difficulty, average marijuana use, initial severity of marijuana involvement, and effects from treatment utilization.

In addition to applications for substance use, motivation appears to play an important role in the reduction of eating disorder symptoms for children and adolescents. In 2005, Ametller and colleagues conducted a study evaluating motivation as a predictor of hospital admission for adolescents meeting criteria for anorexia nervosa. Relying on the Stages of Change model, they reported a staggering $80 \%$ of patients in the precontemplation stage required hospital admission, whereas hospitalization was not required for any patients in the maintenance stage. Moreover, higher levels of motivation were also associated with fewer re-admissions to a hospital. In addition to hospital admission rates, motivation has also been associated with less body dissatisfaction, more adaptive parent-adolescent relationships, and fewer depressive symptoms in adolescent females meeting criteria for an eating disorder (Zaitsoff \& Taylor, 2009). 
Many youth motivation studies comparing treatment outcomes have presented similar findings: pre-treatment motivation predicts outcome (Rodriguez-Cano \& Beato-Fernandez, 2005; Rieger et al., 2000). In 2006, McCuller, Sussman, Wapner, Dent and Weiss used a randomized controlled trial to compare levels of motivation of those who received motivational enhancement therapy to a control group. They estimated $21 \%$ of the treatment effect to be due to amount of motivation at pretest and another $26 \%$ of the treatment effect associated with the motivational component measured during the study, suggesting both initial motivation and sustained motivation throughout therapy significantly impact outcomes in youth and provides strong evidence of motivation as a predictor of treatment outcome in children and adolescents.

In summary, many children and adolescents require psychological services but do not receive them. Those that receive services usually do so in community-based (usual care) settings, though there is insufficient evidence identifying mechanisms of action responsible for change in these, and other, settings. Understanding what variables predict change and influence outcomes in treatment settings is an important step in tailoring interventions and establishing evidence-based practices to improve outcomes. While it has a strong theoretical background, the impact motivation might have on patient symptom reduction is still unclear. Minimal attempts have been made to examine the impact of youth motivation in treatment. What little research exists suggests motivation might be responsible for the magnitude of change occurring during treatment for children and adolescents. In other words, motivation is a potential moderator of youth psychotherapy outcomes.

\section{Limitations of Previous Research}

Previous research lends encouragement to further examination of motivation as a predictor of change in youth, yet it also recommends caution. For instance, semantic precision 
delineating motivation remains in a conceptual quagmire. Without clear definitions of youth motivation established across treatment studies, comparisons of research examining motivation are ultimately meaningless and futile. This is important when considering theoretical guidance in definitions. As an example, West (2005) criticized the Stages of Change model for assuming individuals' motivation progresses in a linear and stable fashion. Further, many studies examining the influences of youth motivation have treated it as a fixed, categorical intraindividual trait rather than a dimensional and multifactorial process (Sainsbury, Krishnan \& Evans, 2004; Whitelaw, Baldwin, Bunton, \& Flynn, 2000). By treating motivation as a categorical trait, valuable information is being condensed into smaller sections that are more amenable to statistical analyses but may not be representative of its true nature. Moreover, exploring motivation as a continuous variable does not violate assumptions of mutual exclusivity required for most analyses. This is a serious limitation as most methods of investigation have used procedures requiring these assumptions to be met (e.g., ANOVA or ANCOVA) to compare differences among treatment groups. However due to error variances, creating mutually exclusive categories from continuous data is unsound.

Additionally, many statistical techniques used also impose assumptions of linearity for valid comparisons to be made. Previous psychotherapy research, however, has shown that with respect to average change trajectories, change in psychotherapy is curvilinear, with most reduction of symptoms occurring within the first few sessions, followed by smaller increments (Cannon, Warren, Nelson, \& Burlingame, 2010; Haas, Hill, Lambert, \& Morrell, 2002) and highly related to initial symptom levels (Merrill, Erekson, Kebert, 2011). Thus, previous statistical methods have been underdeveloped and inappropriate for this type of analysis. More recently, an amendment to clarify the curvilinear relationship of psychotherapy in naturalistic 
settings was posited by Baldwin, Berkeljon, Atkins, Olsen, and Nielsen (2009). They used a multilevel model to suggest patients' rate of change may vary as a function of the amount of treatment received, with small doses of treatment related with quick change and larger doses associated with slower rates of change.

These advances in analyses allow for assessment of motivation over multiple time points that will elucidate information on the improvement of clients and how change occurs over time as suggested by Cady, Winters, Jordan, Solberg and Stinchfield (1996). Most previous analyses were limited to cross-sectional designs that often use small or self-selected samples (Whitelaw, Baldwin, Bunton, \& Flynn, 2000) that ignore the dynamic nature of motivation in child and adolescent treatment and may not accurately describe the relationship between motivation and treatment outcome. No known studies have employed more than three time points (e.g., pretreatment, post-treatment, and follow-up) to track the nonlinear change youth motivation might exhibit in settings where most psychological services are received. This is a serious limitation to previous research. Indeed, examining patterns of change in motivation using regular and frequent data points over the course of treatment would elucidate how motivation relates to youth treatment outcomes and bolster clinician efforts to identify crucial factors that might contribute to more positive outcomes. No known studies have employed rigorous methods of investigation to track the nonlinear change youth motivation might exhibit in settings where most psychological services are received.

Another limitation in the literature is the scarcity of research identifying mechanisms of change, or those processes that predict and influence change (Kazdin, 2004, 2008; Weersing \& Weisz, 2002; Weisz \& Kazdin, 2003), in community settings. Motivation might be responsible for the magnitude of change occurring during treatment for children and adolescents (e.g., highly 
motivated youth might be more likely to engage in therapy, build a stronger alliance with the therapist, and be ready to make changes toward improvement). However, there is an obvious disconnect between research that is conducted in laboratory settings and what clinicians actually practice in real-world settings (Weisz, Weiss, \& Donenberg, 1992), hindering the clinician use of evidence-based practices known to improve functioning while concurrently rendering futile research evidence. Research aimed on mechanisms of change in community settings may begin to bridge this gap and translate empirically sound research into actual practice where most people receive services. In fact, in 1999, DiClemente, Bellino, and Neavins called for more research examining motivation in comorbid psychiatric disorders to narrow the gap between research settings and traditional clinical settings. Identifying mechanisms of change might also transform inchoate theories into more tangible evidences and practices.

\section{Purposes of the Study}

Given limitations presented by previous research, the purpose of this study was to clarify how youth motivation relates to psychotherapy outcomes using appropriate statistical methods for tracking information longitudinally while remaining robust to factors common in "real world" settings (e.g., inconsistent attendance). Within this overall purpose are multiple aims: 1) Examine the association between initial motivation and initial symptom levels; 2) examine how closely initial motivation predicts the rate of change and overall change in symptoms over the course of therapy; and 3) examine how changes in motivation throughout the course of therapy may be related to changes in youth symptoms.

Pursuing these aims is a needed step toward further delineating youth motivation and understanding its relation to symptom reduction in psychotherapy. Further understanding the influences on change in "real life" settings (i.e., traditional clinic settings) has implications for 
optimizing implementation of psychotherapy services. Identification of mechanisms of change in a naturalistic setting allows for more generalizability of results and application in future treatment interventions for children and adolescents receiving psychological services. That is to say, clinicians in settings where most people receive services may have an increased ability to maximize factors known to lead to improved outcomes while minimizing or eliminating ineffective practices not supported by evidence-based research. By so doing, clinicians can better provide for their clients' needs by becoming more aware of known factors that may lead to deterioration. This may be particularly beneficial if clinicians adopt a method of tracking variables known to impact change throughout each session of therapy, assuming moderating factors do not remain constant. Indeed, examining patterns of change in motivation using regular and frequent data points over the course of treatment would elucidate how motivation relates to youth treatment outcomes and bolster clinician efforts to identify evidence-based predictors of change that contribute to more positive outcomes.

\section{Hypotheses}

The following hypotheses are based on the aims of this study and the above summarized literature:

1. Levels of motivation will change in a nonlinear fashion over the course of treatment.

2. Initial motivation will be associated with initial symptom levels.

3. Initial motivation will be predictive of overall change over the course of psychotherapy.

4. Initial motivation will predict the rate of change over the course of psychotherapy. More specifically, lower initial levels of motivation will be predictive of slower rates of change. 
5. Increases in motivation over the course of treatment will be predictive of faster rates of change, and decreases in motivation over the course of treatment will be predictive of slower rates of change.

\section{Method}

This study was conducted in the context of a broader ongoing research program examining child and adolescent psychotherapy processes and outcomes. Consequently, data for the present study were collected as part of the larger project.

\section{Participants}

A power analysis was conducted with $\mathrm{G}^{*}$ Power (Faul, Erdfelder, Buchner, \& Lang, 2009) using a .95 desired statistical power and anticipated effect size of .30, an estimate based on Hettema, Steele, and Miller's (2005) findings, and a .05 alpha level. Considering the conglomerate post-treatment effect size of motivation over 72 studies was reportedly .77 , using estimates from one-year follow-up (.30) is conservative, yet it seems appropriate given the mixed findings in the literature. Additionally, it minimizes possible impact from allegiance effects (Botella \& Beriain, 2010; Lambert, 1999). Given this information, at least 49 participants are required to have a $95 \%$ chance of detecting differences, if they exist.

The sample for this study include 150 youth ages $12-17$, and information from their primary caregivers, who are receiving psychotherapy treatment from one of three community mental health clinics located in the Intermountain West; it is estimated these clinics serve a region of approximately 530,000 people. Participants were recruited at their intake appointment prior to receiving treatment. They were informed of the study's purpose and asked to participate in this research which explores possible predictors, or enhancers, of treatment outcome in youth receiving treatment. Participation in the study was voluntary and did not impact the treatment 
they received if they declined to participate. All participants were able to be involved in the study assuming they fit the age requirements specified and could read and speak English fluently enough to complete measures given. Over $90 \%$ of those recruited agreed to participate.

Youth and their parents were demographically representative of people seeking outpatient treatment in the Intermountain West region, with slightly greater representation of minority and low socioeconomic status individuals (United States Census Bureau, 2010). Approximately 61\% of the sample self-identified as male $(n=91)$ and $39 \%$ self-identified as female $(n=59)$. The average age of participants was $14(M=14.25, S D=1.61)$. Ethnicity of the population was approximately $81 \%$ Caucasian, 9\% Hispanic/Latino, 3\% Hispanic/White, 1\% African/White, 1\% Asian/Pacific Islander, 1\% African-American and 4\% other. Primary diagnoses varied greatly, with $8 \%$ of participants meeting criteria for Anxiety Disorder Not Otherwise Specified $(n=12)$, 7.3\% for Oppositional Defiant Disorder $(n=11), 6.7 \%$ for Bipolar II Disorder $(n=10), 6 \%$ for Mild Major Depressive Disorder $(n=9)$, and 5.3\% for Adjustment Disorder with Disturbance of Conduct $(n=8)$. The remaining 45\% were diagnosed with disorders fairly typical for youth (e.g., Attention-Deficit Hyperactivity Disorder; Conduct Disorder; $n=67$ ) or were not given a primary diagnosis by the clinician $(n=33)$. In these community mental health settings, a diagnosable condition is required after the fourth session for continued treatment, so the absence of a diagnosis is most likely the result of the client not returning after the fourth session.

\section{Measures}

Outcome. Treatment outcome (change in symptoms) was measured using the Youth Outcome Questionnaire-2.01 (Y-OQ; Burlingame et al., 2001, 2004, 2005). The Y-OQ is a parent-report measure designed to be sensitive to changes in client (ages $4-17$ ) psychological functioning over time (Burlingame, et al., 2001; McClendon et al., 2011). It yields a total score 
and six separate subscale scores identifying various emotional and behavioral problems. The total score is calculated by summing the six scales and is indicative of psychological distress. It takes approximately 8-10 minutes to complete and consists of 64 items rated on a 5-point Likert scale: $0=$ Never, $1=$ Rarely, $2=$ Sometimes, $3=$ Frequently, $4=$ Almost always. Scores range from 16 to 240, with higher scores indicating greater distress; negative total scores are possible due to some items being reverse scored. The utility of the Y-OQ has been demonstrated by previous research (Burlingame et al., 2004). The total score provides the highest estimates of reliability with a satisfactory level of internal consistency (Chronbach's alpha $=.97$ ) and a 6-week testretest reliability of .76 (Burlingame et al., 2004). In addition, the Y-OQ exhibits good concurrent criterion validity with the Child Behavior Checklist (CBCL; Achenbach, 1991) and the Conners' Parent Rating Scale (CPRS; Conners, 1990). The validity of the Y-OQ has also been supported by its ability to distinguish between clinical and normative samples (Burlingame et al., 2004). Reliable change in treatment has occurred if the individual's total score has adjusted at least 13 points (Burlingame et al., 2004). In addition, the Y-OQ has been shown to be sensitive to change in multiple settings (Berrett, 1999; Burlingame et al., 2001; Mosier, 1998).

The Youth Outcome Questionnaire Self-Report (Y-OQ-SR) is a parallel version of the YOQ designed to be completed by adolescents (ages $12-18$ ). Given the simplified adaptation of questions used on the Y-OQ-SR, it takes approximately seven minutes to complete (Wells et al., 1996). Test-retest reliability $(r=.89)$ and internal consistency $(\alpha=.95)$ estimates are similar to its parent counterpart. It has also revealed concurrent criterion validity when compared to other youth self-report measures, such as the CBCL and Behavior Assessment System for Children, Second Edition (BASC-2), with “excellent validity” (Burlingame et al., 1995; Ridge, Warren, 
Burlingame, Wells \& Tumblin, 2009). Y-OQ and Y-OQ-SR total scores will be used in the analyses.

Psychosocial functioning. The CBCL is a standardized questionnaire designed to assess 120 different child problem behaviors in reference to the prior six months. It consists of 113 items rated on a 3-point scale. It provides data in three major sections: 1) Eight empiricallyvalidated syndromes (withdrawn, somatic complaints, anxious/depressed, social problems, thought problems, attention problems, delinquent behavior, and aggressive behavior); 2) Six DSM-oriented scales: (affective, anxiety, somatic, attention-deficit, oppositional-defiant, and conduct related problems); and 3) Three competency scales: (activities, social, and school). The CBCL is thought to provide good evidence of reliability with internal consistency coefficients for the Syndrome scales, DSM-oriented scales, and Competence scales ranging from .78 to $.97, .80$ to .93 , and .63 to .79 , respectively (Achenbach \& Rescorla, 2007). Additionally 8 -day test-retest coefficients range from .86 to .94 for Syndrome scales, .82 to .91 for DSM-oriented scales, and .82 to .93 for Competence scales (Achenbach \& Rescorla, 2007). The CBCL was administered only to caregivers at intake as a means of assessing initial problematic behaviors.

Motivation. The Treatment Support Measure - Youth (TSM-Y; See Appendix) is a 42item youth self-report measure (for ages 12-17) that was designed as a clinical support tool for therapists to use when clients deviate from expected therapeutic trajectories. It contains domains thought to contribute to worsened outcomes: youth self-efficacy, youth social support, youth motivation for treatment, and the youth's perception of the therapeutic alliance. The TSM-Y uses a Likert-like scale to measure youth perceptions of problems. Reliability estimates from a community sample of 189 parents of youth aged 4-17 and 120 youth aged 10-17 yielded overall 4-week test-retest reliability coefficients for the TSM-P and TSM-Y measures to be estimated 
at .92 and .91 , respectively. Subscale alpha estimates ranged from .77 to .89 for the TSM-P and from .84 to .88 for the TSM-Y. Preliminary TSM items have initially demonstrated some sensitivity to change (Warren, et al., 2008). The TSM-Y motivation subscale (TSM-YM) also yielded adequate internal consistency $(\alpha=.81)$ and test-retest reliability $(r=.82)$. It includes seven Likert-format items that were adapted in part from the University of Rhode Island Change Assessment Questionnaire (URICA; McConnaughy, DiClemente, Prochaska, \& Velicer, 1989; McConnaughy, Prochaska, \& Velicer, 1983) which is considered a gold standard measure of motivation using the TTM of change. Questions from the URICA have been adapted to be age appropriate for the reading level of the population of interest (ages 12-17) and incorporate theoretically sound principles of motivation (e.g., internal vs. external; Deci \& Ryan, 1991) assumed to relate to mental health settings (e.g., "I'm not going to change the way I am by coming to therapy").

\section{Procedures}

To examine the relationship of putative moderator effects and to further clarify trajectories of motivation, in relation to psychotherapy outcomes, a longitudinal design was employed. Cady et al. (1996) recommended assessing motivation at multiple time points in order to elucidate information regarding its effect on change and expected trajectory patterns. Laurenceau, Hayes, and Feldman (2007) also recommended measures used to assess potential moderators should be evaluated over multiple time points to examine when effects might take place as well as the degree of these effects. Previous research suggests the rate at which youth symptoms change in psychotherapy is nonlinear, with the greatest amount of change occurring within the first few sessions for those with high initial severity (Hayes et al., 2007) and a "good enough" set point being reached over the course of therapy (Baldwin et al., 2009). For these 
reasons, measures of motivation were administered across approximately 11 time periods.

Because research suggests most change occurs in the first few sessions of therapy, measures were distributed as follows: at intake, just prior to each of the first five sessions, and approximately every three weeks thereafter.

Following a standardized script (See Appendix) explaining the purpose and details of the study at intake, clients were invited to participate by completing consent (See Appendix) and assent forms (See Appendix) as well as an assessment battery which includes the age appropriate versions of the TSM-Y, CBCL, and Y-OQ prior to their first therapy session. Research assistants administered the TSM-Y and Y-OQ to participants at their designated clinic before the first five therapy sessions and approximately every three weeks thereafter. The assessment battery required approximately 15 minutes time to complete. As compensation, participating youth and their parent or caregiver each received $\$ 10$ at the first session. An additional $\$ 10$ was given to both parent/caregiver and child/adolescent prior to their fifth therapy session, pending continued participation in the study. Additionally, youth were allowed to select a small prize (worthy approximately one dollar) each time they completed the forms. Families who continued participation in the study for either six months or until treatment was considered completed through the clinic (whichever came first) were entered into a drawing for the chance to win 1 of $10 \$ 100$ cash prizes.

Most therapy appointments occurred on a weekly basis. However, frequency of sessions varied widely due to differences in client needs, therapist/client availability, and therapeutic goals. Therefore, psychotherapy services were measured by dose rather than by session and included intake sessions, individual therapy, and family therapy. Psychoeducational skill- 
building groups and medication management were also services provided at these clinics, but they were not included in this study.

Therapists varied in their training and included graduate interns, master, and doctorallevel therapists. The clinic settings used a wide variety of therapeutic orientations, the most common of which was cognitive-behavioral techniques. No information that might have influenced treatment was given to therapists, so as to allow treatment to be considered usual care and as representative of outpatient settings as possible. Information regarding diagnosis, demographic information, number of sessions attended, and how often sessions were attended was retrieved from the clinic settings at the conclusion of the data collection process and used in data analysis. Data were collected over a period of about two years.

\section{Analysis}

In order to establish the best classification of the data based on longitudinal patterns of change, a series of growth models (GM; Meredith \& Tisak, 1990) were applied. GM handles longitudinal data and accounts for patterns of change among distinct trajectories (Muthén \& Asparouhov, 2008). Main effects and patterns of change in motivation and youth symptoms over the course of treatment were examined within the GM series. Since GM assumes equidistant time points between observations, a growth model with individually-varying times of observation was utilized to handle the type of data common in real world settings (i.e., varying lengths between psychotherapy sessions). The statistical program Mplus, version 7.11 (Muthén \& Muthén, 2008) was used to conduct analyses.

Most previous studies in the literature used linear procedures, or fewer than four time points, to measure changes in individual motivation. GM is sensitive to nonlinear change and can be used to track multiple individual data points longitudinally. By so doing, GM is clearly 
advantageous when compared to other common statistical methods for delineating trajectories of change. This is considered to be a necessary step in illuminating effects of youth motivation on treatment outcomes and providing a richer definition of motivation in psychotherapeutic contexts.

GM is also an effective method of analytically identifying moderators of therapy outcomes, because it allows for examination of moderator effects by comparing changes in motivation with changes in youth symptoms. If a pre-treatment, between-subjects covariate (e.g., initial level of youth motivation) is a statistically significant predictor of the rate or shape of change for psychotherapy outcome, it is considered a moderator of change (Laurenceau, et al., 2007) and would provide evidence for hypothesis 2 . While it is important to know if youth motivation is a significant predictor of change in psychotherapy, it is perhaps even more imperative to know the magnitude of change motivation effects and how it might change over time. Beyond the dichotomous decision making used in significance testing, the slope growth of youth motivation in treatment outcome portrays a clearer picture of its importance in psychotherapy.

Demographic information (e.g. age; gender; ethnicity) were evaluated for significant differences between participants and potential impact on the dependent variables. No significant differences were found that might have impacted the generalizability of the results.

\section{Results}

To estimate GM parameters, Mplus utilized ML, which is a maximum likelihood estimation that can be used for complete and incomplete data (Muthén \& Shedden, 1999). Fullinformation ML was used to account for missing data points associated with measures of treatment outcome and motivation (Little \& Rubin, 2002). Additionally, Hipp and Bauer (2006) 
recommend using multiple random sets of start values in order to avoid converging on a local solution (i.e. false maximum likelihood). In this study, 500 random sets of start values were requested for each model, with the 20 best retained for final optimization. All models converged on a replicated solution and can confidently be assumed to reflect a "real" maximum likelihood.

Missing data in studies done in usual care settings is a common problem (Baldwin et al., 2009), and it is important to know whether the missing data are missing completely at random (MCAR) or missing for some other reason (MNAR). Missing data was analyzed using Little's MCAR test (Little, 1988): $\chi^{2}=1415.082(d f=1524 ; p=.978)$, indicating the data is indeed missing at random (i.e., no pattern was identified among the missing data). Further analyses determined that only four of the 149 participants attended eleven sessions of psychotherapy. This resulted in more than $97 \%$ missing data at the eleventh time point. Consequently, this time point was not incorporated into the analyses. Additionally, ML excluded 10 more participants from analyses due to insufficient time point data, resulting in 136 remaining cases (of the 150 sample participants) with a maximum of 10 sessions attended (out of 11 total collected).

\section{Hypothesis 1: Youth Motivation Trajectories}

Most statistical approaches output aggregate group changes as linear comparisons. While this appropriately answers some specific questions, it tends to limit the richness of data and may omit significant individual trajectories that may be important in clarifying patterns of motivation in youth if these trajectories are nonlinear. Growth models with linear, quadratic, square root, and cubic growth were compared to determine the best fit for examining change over time for youth motivation and youth symptom variables using self- and parent-reported data. These models allow a variety of straight and curved trajectories to capture different rates of improvement at different stages of treatment. The model that provided the best description of the 
data with relatively few parameters and classified individuals into the fewest overall trajectories was used in the analysis. Schwarz's Bayesian Criterion (BIC), Akaike's Information Criterion (AIC), and -2 Log Likelihood were used as indices of goodness of fit to address hypothesis 1, given their strong support as effective indicators of choosing the model which best recovers the sample's true parameters in growth models (McLachlan \& Peel, 2000; Yang, 2006). Further, individual trajectory slopes of motivation were compared to identify specific patterns of motivation trajectories over the course of therapy.

A number of statistical tests and indices were applied to the growth models to determine a modeled aggregate trajectory that best explains the data. Goodness of fit indices were compared for each model and suggested the square root transformation of weeks in treatment best fit the data (Figure 2).

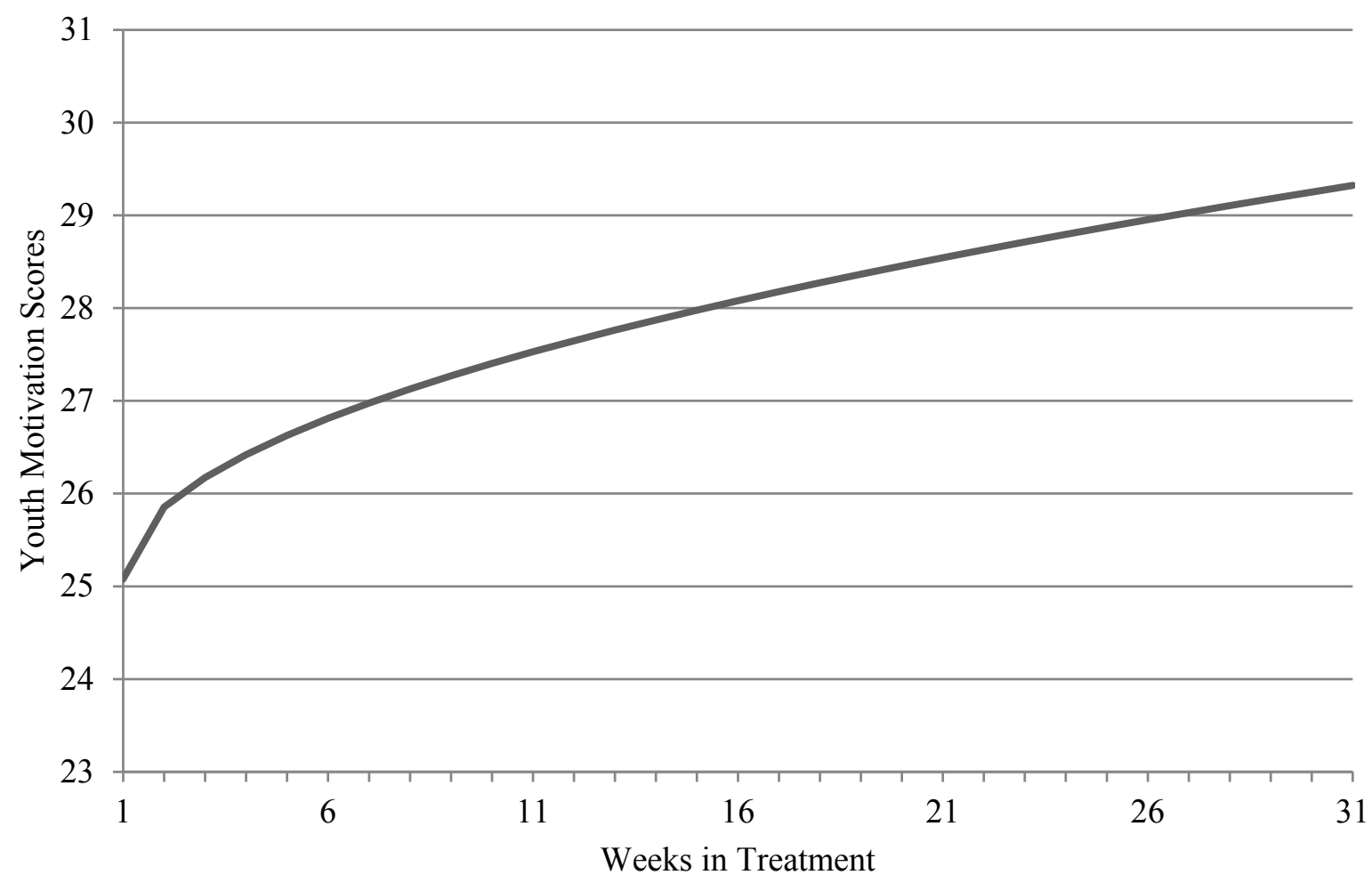

Figure 2. Average Youth Motivation Change Trajectory 
A motivation trajectory that fits a square root pattern fits theoretical expectations. This analysis indicated that perceived change in both parent and youth-reported symptoms and youthreported motivation followed a curvilinear pattern, which suggested youth are likely to experience significant gains in motivation to change in the initial sessions of therapy that eventually level out as treatment progresses. This mimics extant precedents suggesting curvilinear trajectories best model treatment progress and recovery (e.g. Finch, Lambert, \& Schailje, 2001; Lambert, Whipple, Bishop, Vermeersch, Gray, \& Finch, 2002; 35 Spielmans, Masters, \& Lambert, 2006). Consequently, all future analyses assume this square root transformation.

\section{Hypothesis 2: Initial Motivation and Intake Symptoms}

To address the hypothesis that initial motivation would be associated with intake symptoms, a univariate growth model was used to calculate means and standard deviations of YOQ and youth motivation scores at intake (Table 2) as well as overall Y-OQ and youth motivation change scores following treatment termination (Table 3). Regression coefficients were computed to examine the relationship between intake symptom levels and initial levels of youth motivation. It was expected that higher levels of symptoms would relate to greater levels of motivation to change and that low levels of intake symptoms would be associated with lower levels of motivation. The regression coefficients between initial levels of youth motivation and intake symptoms were statistically significant for both parent and self-report $(b=-181.93 ; p$ $=.005 ; b=-234.68 ; p=.002$, respectively). In this case, it suggests when initial symptoms scores were high, motivation scores were low, or when motivation scores were high, symptoms levels were low. This finding describes an inverse relationship from what was hypothesized. 
Table 2

Unstandardized Mean Intercepts and Slopes of Y-OQ and TSM-YM

\begin{tabular}{llll} 
& Estimate & $S E$ & $p$ \\
\hline Y-OQ Intercept & 65.737 & 8.801 & $<.001$ \\
Y-OQ Slope & -2.349 & 1.345 & 0.081 \\
Y-OQ-SR Intercept & 64.538 & 15.093 & $<.001$ \\
Y-OQ-SR Slope & -9.624 & 2.137 & $<.001$ \\
TSM-YM Intercept & 25.139 & 1.322 & $<.001$ \\
TSM-YM Slope & 0.578 & 0.210 & 0.006 \\
\hline
\end{tabular}

Table 3

Intake and Pre-Post-Change Means and Standard Deviations of Y-OQ, TSM-YM, and CBCL

\begin{tabular}{lll} 
& Mean & $S D$ \\
\hline CBCL Total & 64.55 & 8.78 \\
CBCL Internalizing & 64.88 & 9.88 \\
CBCL Externalizing & 61.73 & 10.50 \\
Y-OQ & 67.09 & 35.76 \\
Y-OQ Change & -5.77 & 27.58 \\
Y-OQ-SR & 65.11 & 36.86 \\
Y-OQ-SR Change & -20.97 & 27.49 \\
TSM-YM & 25.26 & 6.18 \\
TSM-YM Change & 1.38 & 5.11 \\
\hline
\end{tabular}

\section{Hypothesis 3: Initial Youth Motivation Predicting Overall Symptom Reduction}

Evidence for initial motivation predicting overall change in therapy has been well demonstrated in the literature (King et al., 2009; McCuller et al., 2006); however, methods of approaching this question have varied greatly. It was expected that youth motivation at intake would predict overall symptom reduction for both youth and parent-reported symptoms. Two regression models with initial motivation predicting symptom reduction (final Y-OQ score), 
while controlling for symptom severity (first Y-OQ score) were run using Mplus with ML estimation. This method of investigation evaluates the effects initial motivation had on overall change in therapy, while accounting for initial symptom severity. Thus, it is likely to provide an accurate depiction of the contribution motivation has on treatment in its early stages.

Results from the regression model comparing the relationship between levels of youth motivation at intake and overall symptom reduction for youth-reported symptoms, while controlling for initial symptom severity, $(b=1.034 ; p=.5)$ were non-significant. Similarly, results comparing the relationship between intake youth motivation scores and overall symptom reduction for parent-reported symptoms, while controlling for symptom severity, $(b=3.14 ; p$ $=.173$ ) were also non-significant. Even though initial youth motivation was not identified as a predictor of overall change throughout the course of therapy, it was predictive of symptom severity at the last session of psychotherapy attended.

\section{Hypothesis 4: Initial Youth Motivation Predicting Rate of Change}

It was further projected that intake youth motivation scores would be associated with rates of symptom change. In other words, the predictive power of initial levels of youth motivation on how rapidly change occurs according to both parent and youth reports was examined. The results indicated no significant relationship between intake youth motivation scores and rates of symptom change for either youth $(b=.447 ; p=.141)$ or parent $(b=.198 ; p$ $=.382$ ) reporters in the current sample. Together, these findings suggest initial motivation was not predictive of change in symptoms or rate of change at the $p<.05$ level, which does not support youth motivation as a moderator of change in treatment outcomes.

Additional analyses yielded evidence for wide variability within individual rates for parent-reported change $(b=4587.008 ; p<.001)$, self-reported change $(b=4571.601 ; p=.002)$, 
and youth motivation $(b=30.322 ; p<.001)$ over the course of treatment, when observing session-by session differences. A sample of motivation scores was randomly selected from seven participants that depicts the degree of variability common over the course of treatment (Figure 3). As is demonstrated in the figure, motivation to change varies by start points, end values, and rate for each individual. Similar variability was present when examining changes in outcome.

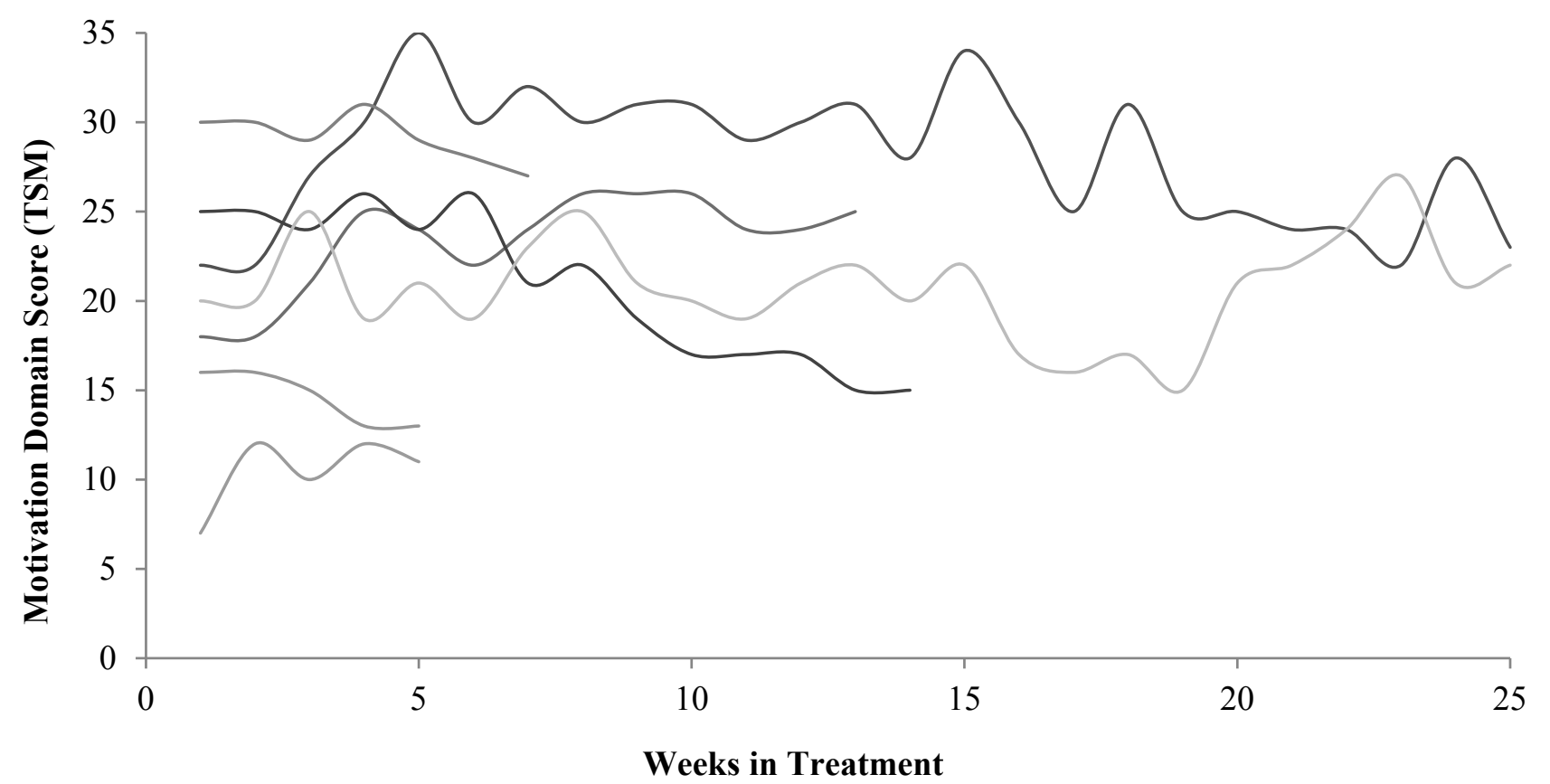

Figure 3. A Randomized Sample of Individual Motivation Trajectories

\section{Hypothesis 5: Changes in Motivation with Symptom Reduction Rate}

Changes in youth motivation scores were anticipated to be associated with changes in $\mathrm{Y}$ OQ scores over the course of therapy. A univariate growth model indicated youth motivation significantly increased over the course of therapy $(b=.578 ; p=.006)$, and Y-OQ scores decreased significantly over the course of treatment, according to self-report $(b=-9.624 ; p$ $<.001)$, but not parent-report $(b=-2.349 ; p=.081)$. 
This means that for every psychotherapy session attended, clients averaged an increase of .578 units on the motivation scale. Moreover, for every session of psychotherapy attended clients reduced problematic symptoms by 2.349 units and 9.624 units, according to parent and self-report, respectively (Figure 4). Additionally, results from a multivariate model revealed that the slope for motivation to change was negatively predictive of the slope for mental health symptoms as reported by youth $(\beta=-5.53 ; p<.001)$ and their caregivers $(\beta=-3.23 ; p$ $<.001)$. In other words, youth who showed greater increases over time in motivation to change were those who also showed greater decreases in mental health symptoms.

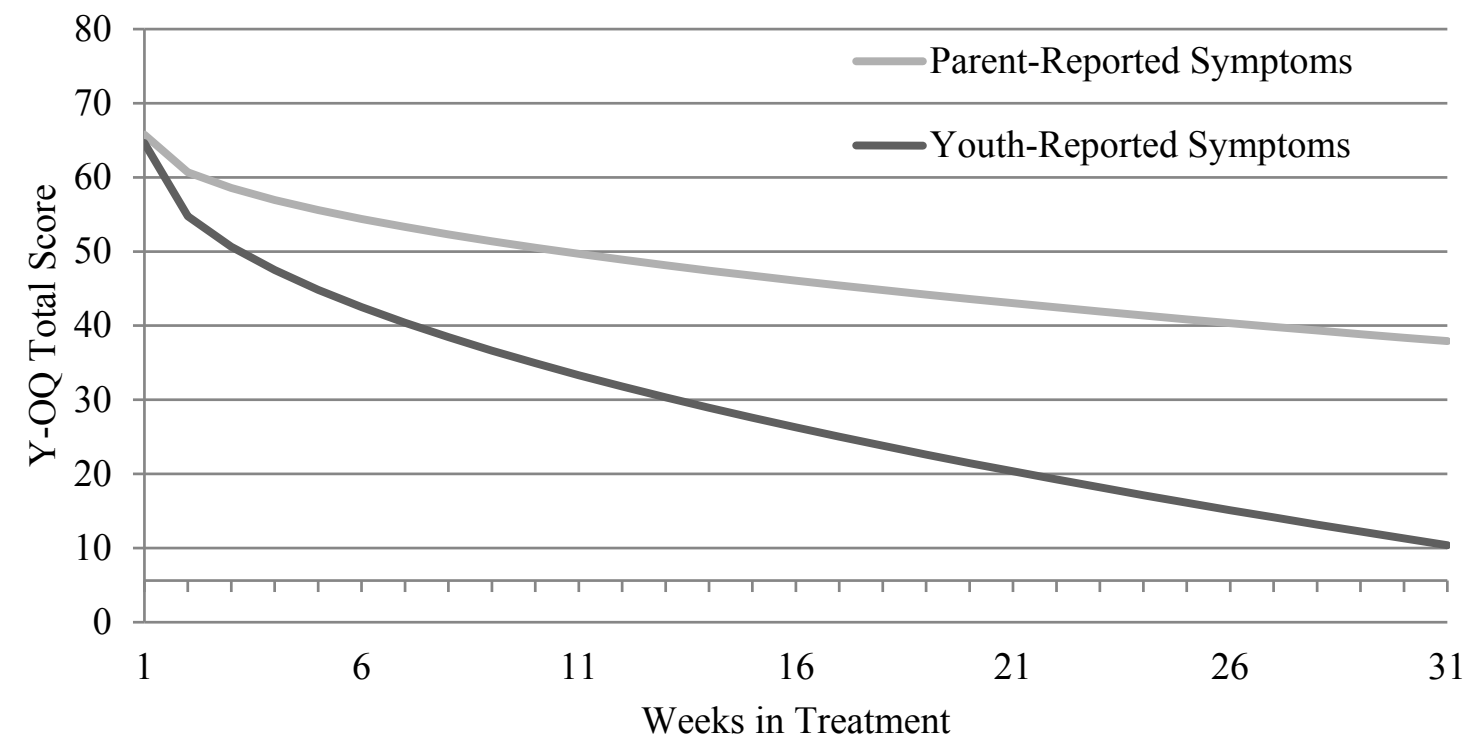

Figure 4. Average Youth and Parent-Reported Symptom Change Trajectories

\section{Discussion}

To date, only a few studies have examined the relationship between youth motivation and youth psychotherapy outcomes. The extant literature suggests motivation is related to participation, engagement, and the mental health functioning of children and adolescents (Ansari, Gouthro, Ahmad, \& Steele, 1996; Joe, Simpson, \& Broome, 1998; Kazdin, Mazurick, \& Seigel, 1994; Zuroff, et al., 2007). This study bolsters previous findings by including youth perceptions 
of change in symptoms, examining whether initial levels of youth motivation are related to psychotherapy outcomes and rates of change, examining whether changes in youth motivation over the course of treatment were associated with rates of symptom change, and by evaluating how youth motivation may change during psychotherapy. Importantly, these factors were examined in the context of community mental health settings, where most treatment usually occurs. A longitudinal and multi-level design was employed to capture change trajectories of motivation using multiple time points, with the intent of more precisely measuring relationships between youth motivation and outcomes in psychotherapy.

An inverse relationship was found between intake motivation scores and initial symptoms levels, suggesting that youth reported greater motivation to change when they experienced lower symptom severity, or they felt less motivated to change when symptom levels were high. This could be the result of youth motivation being sapped when they feel they do not have adequate resources to manage mental health symptoms. Conversely, as mental health symptoms subside, youth are likely to experience greater self-efficacy and devote more energy to making changes in their lives (Bandura, 1997). The idea of motivation and psychological symptoms being linked with self-efficacy or other "self" driven factors, like self-determination or autonomy (desire for self-initiated actions), is corroborated by well-established theory (Self-Determination Theory; Deci \& Ryan, 1985, 1987, 1991).

Previous research (Melnick, De Leon, Hawke, Jainchill, \& Kressel, 1997; RodriguezCano \& Beato-Fernandez, 2005) suggested initial levels of motivation to change is a contributing moderator to overall youth psychotherapy outcomes, yet findings from this study failed to support this assertion. Moreover, the second hypothesis, which stated intake youth motivation levels would be associated with rates of symptom change, after accounting for initial levels of 
youth symptoms, was also not supported by the study. These null findings could be the result of treatment setting or differences in presenting concerns.

More specifically, most studies examining the impact of motivation on treatment outcomes have concentrated on low-motivation populations (e.g., substance abuse, eating disorders, inpatient settings; Sutton, 2001) and may not adequately generalize to usual care settings (Garland, Hurlburt \& Hawley, 2006; Kazdin, 2003; Weersing \& Weisz, 2002; Weisz et al., 2005), such as the settings utilized in this study. For instance, Melnick, et al. (1997) tracked over 1,000 adolescents and over 1,400 young adults in residential therapeutic communities aimed at treating substance disorders and confirmed the importance of motivational factors in the treatment process, regardless of age. Rodriguez-Cano and Beato-Fernandez (2005) provided evidence for the necessary role of motivation for clients who attended an outpatient setting specifically for eating disorder treatment. Initial motivation has been predictive of treatment outcomes in adolescent, low motivaiton populations, (Lambie \& Sias, 2006), but motivation to change might not be as crucial for treatment of those with more general concerns-like those often found in usual care settings.

Understanding youth motivation within the context of community-based settings is especially important considering the large degree of client variability often present in these settings. Given the results from this study, it appears that the importance of initial motivation in psychotherapy becomes negligible when viewed aggregately in naturalistic settings. Put another way, the role of initial motivation in youth psychotherapy may not be important for all youth referred for treatment. Significant individual variability was observed across youth motivation trajectories, which may suggest unique trajectories of motivation for different subsets of youth concerns (e.g., eating and substance abuse disorders vs. mood and anxiety disorders). This could 
explain the lack of evidence supporting youth motivation as a moderator of treatment outcomes. However, it is also possible that psychotherapeutic interventions (e.g. rapport building; engagement) may have preeminently addressed issues of motivation during the first few sessions of treatment.

Although initial motivation was not predictive of change trajectories in youth symptoms, results indicated session-to-session changes in motivation were associated with client improvement. This speaks to the importance of recognizing motivation as a dynamic and fluctuating construct in psychotherapy, and not a static personal attribute. Motivation to change is likely to increase or decrease for a number of reasons: symptom levels, critical life events, cognitive evaluation or appraisal, recognition of negative consequences, positive and negative external incentives, or even social interactions (including therapist - client interactions; Allen et al., 1999). Understanding the cause of changes (even micro changes) in motivation to change may support clinicians in eliciting more positive changes and reducing harmful changes in their clients.

Identifying session-by-session changes in youth motivation was another aim of this study. Motivation of youth significantly increased, on average, over the course of therapy. This is not surprising given results of previous research using pre-post designs (McCuller, Sussman, Wapner, Dent and Weiss, 2006). Yet, the relatively infrequent assessment of motivation in previous studies precluded their examining non-linear patterns of change in motivation. By assessing motivation frequently over the course of treatment, this study demonstrated that youth motivation typically followed a curvilinear trajectory, signifying that youth are likely to experience significant gains in motivation to change in the initial sessions of therapy that eventually level out as treatment progresses. 
Reduction of psychological symptoms is one plausible explanation for increases in motivation. This study provides some evidence to support the inverse correlation between motivation and symptom levels, so it would be expected that symptom levels follow a reflective pattern of motivation. Indeed, treatment outcome research suggests large changes in symptom levels within the first few sessions of psychotherapy (Hayes, et al., 2007), following a curvilinear trajectory—similar to motivation, just in the opposing direction (motivation increases and symptoms decrease). This study does not support causal claims in the relationship between motivation and symptom levels, but it does support the idea that motivation is likely to increase as symptoms are reduced.

The general trend of motivation increasing most dramatically in the first few sessions could also be the result of clinician efforts to build a strong alliance, establish expectations for psychotherapy, and increase engagement early on in order to remove potential barriers to client progress in the future. These factors (especially the therapeutic alliance) have been shown to be associated with positive outcomes (Karver, Handelsman, Fields, \& Bickman, 2006) and may explain what clinicians can focus on to build motivation in early psychotherapy sessions, but it neglects other external influences.

Factors outside of the clinician's control (e.g., parental influence, peer influence, genetics, sociocultural ideologies, significant life event, etc.; Allen et al., 1999) may also contribute to rapid changes in motivation early in treatment. For example, a youth client who enters psychotherapy largely due to parental prodding may not be very internally motivated to change. Clinician may help encourage youth shift from an external motivation to an internal motivation, but the clinician lacks the ability to instill this change in youth if it is unwanted. 
Certainly, external factors might comprise an inexhaustible list of influences on motivation trajectories.

Clinicians may have very little impact changing external motivating factors for clients; however, the literature supporting MI as useful tool for increasing motivation to change is impressive. By eliciting change talk, increasing autonomy, and shifting to internal motivating factors, clients tend to get better (Aharonovich, et al., 2008). Additionally, MI is considered an additive tool and can be used in adjunct to most treatment packages — which may be especially beneficial in usual care settings. However, it is important to note that using motivational enhancement techniques may be ineffective, or even harmful, when individuals are already following expected outcome trajectories and highly motivated (Ondersma et al., 2009).

Even though most youth experienced increases in motivation following a curvilinear course, given the research on treatment failure and dropout rates for youth (Warren, et al., 2010), it was expected that some youth would experience a decline in motivation over the course of treatment or prematurely terminate treatment. Youth motivation may not be a significant predictor of positive treatment outcomes, but it may still be an important contributing factor if the client is not consistently attending sessions, not engaging in treatment, or is at risk for premature termination (Ansari, Gouthro, Ahmad, \& Steele, 1996; Kazdin, Mazurick, \& Seigel, 1994).

\section{Limitations}

This study yields potentially important findings regarding the relationship between youth motivation and psychotherapy outcomes, yet the results must be considered in light of the study's limitations. One such limitation to this study was the limited number of measures used. The YOQ and TSM-YM were selected as measures of symptoms and youth motivation, 
respectively, due to their good reliability and supportive evidence for validity, yet it would be ideal to use multiple methods of assessment. In routine care settings, however, use of multiple measures often becomes cumbersome and unfeasible. Furthermore, the TSM-YM was designed as a practical screener to quickly assess problematic areas in motivation. Having only seven items included in the measure increases its utility in usual care settings, but it may lack discriminatory power as a precise research instrument.

While the sample of this study provided an adequate number of participants to detect meaningful changes over time, the mode number of sessions was one, and the median number of sessions was four. Thus, there is a high level of confidence that intake information is representative of the sample, yet confidence levels in statistics provided for participants remaining in the study beyond 6-8 sessions decreases over time due to a diminished sample size. A larger sample size observing participants who complete at least 8-10 sessions may be more amenable to tracking changes over time.

Finally, a comparison group was not employed in this study. Use of a comparison group would be beneficial in determining whether changes in symptoms and youth motivation were a result of treatment interventions or a result of extraneous factors (e.g., regression/progression to the mean; youth maturation).

\section{Implications and Future Research}

This study attempted to further elucidate the relation between youth motivation and youth symptoms and outcomes in community mental health settings. Youth motivation to change is rarely assessed in traditional clinic settings despite the fact that most youth are generally referred for psychotherapy services based on parental concern derived from observing problematic external behaviors (Barrett \& Rappaport, 2011; Skowyra \& Cocozza, 2007). Identification of 
how youth motivation relates to psychotherapy outcomes in naturalistic settings allows for broad generalizability of results; however, extending research tracking youth motivation over time may have even greater import in residential treatment centers, alternative schools, and medical settings, where motivation is thought to be a significant moderator of treatment outcomes.

Differing diagnoses, or categories of disorders, may also explain a large degree of variance in initial levels of motivation and changing rates of motivation. If certain clusters of problematic behaviors exemplify unique trajectories of motivation, it would be important for clinicians to know how much effort to spend increasing motivation to prevent dropout rates or treatment deterioration.

Correlates that contribute to motivation in treatment, and how they contribute, are still unclear and imprecise. It is recommended that future research examines both internal (psychological distress, self-efficacy, autonomy, self-determination) and external (critical life events, sociocultural, family factors) influences on motivation in relation to treatment outcomes.

Future studies are encouraged to control for motivation interventions in therapeutic settings to more rigorously account for the strength of the relationship between youth motivation and treatment outcomes. In addition, it may be beneficial to stratify the sample population by motivation level to determine the relationship between outcome and motivation trajectories given subsets of motivation (e.g., high, medium, and low). This would likely be most beneficial if the motivation assessment tool included a large set of items known to discriminate between levels of motivation (or readiness to change), such as the URICA. 


\section{References}

Abblett, M. R. (2002). Motivation for change in psychotherapy: The relationship between the transtheoretical model and self-determination theory and prediction of clinical services utilization. Dissertation Abstracts International, 63, Retrieved from EBSCOhost.

Achenbach, T.M. (1991). Manual for the child behavior checklist/4-18 and 1991 profile. Burlington, VT: University of Vermont Department of Psychiatry.

Achenbach, T.M., \& Rescorla, L.A. (2004). The Achenbach System of Empirically Based Assessment (ASEBA) for ages 1.5 to 18 years. In M. Maruish (Ed.), The use of psychological testing for treatment planning and outcome assessment: Volume 2 (3rd ed.). Mahwah, NJ: Lawrence Erlbaum Associates.

Aharonovich, E., Amrhein, P. C., Bisaga, A., Nunes, E. V., \& Hasin, D. S. (2008). Cognition, commitment language, and behavioral change among cocaine-dependent patients. Psychology of Addictive Behaviors, 22, 557-562. doi:10.1037/a0012971

Alegría, M., Chatterji, P., Wells, K., Cao, Z., Chen, C., Takeuchi, D., \& ... Meng, X. (2008). Disparity in depression treatment among racial and ethnic minority populations in the United States. Psychiatric Services, 59, 1264-1272. doi:10.1176/appi.ps.59.11.1264

Ametller, L., Castro, J., Serrano, E., Martinez, E., \& Toro, J. (2005). Readiness to recover in adolescent anorexia nervosa: Prediction of hospital admission. Journal of Child Psychology and Psychiatry, 46, 394-400. doi: 10.1111/j.1469-7610.2004.00360.x

Amrhein, P. C., Miller, W. R., Yahne, C. E., Palmer, M., \& Fulcher, L. (2003). Client commitment language during motivational interviewing predicts drug use outcomes. Journal of Consulting and Clinical Psychology, 71, 862-878. doi:10.1037/0022006X.71.5.862 
Angold, A., Costello, E. J., \& Erkanli, A. (1999). Comorbidity. Journal of Child Psychology and Psychiatry, 40, 57-87.

Ansari, A., Gouthro, S., Ahmad, K., \& Steele, C. (1996). Hospital-based behavior modification program for adolescents: Evaluation and predictors of outcome. Adolescence, 31, 469476.

Appleyard, K., Egeland, B., \& Sroufe, L. (2007). Direct social support for young high risk children: Relations with behavioral and emotional outcomes across time. Journal of Abnormal Child Psychology, 35, 443-457. doi:10.1007/s10802-007-9102-y

Baker, A., Richmond, R., Haile, M., Lewin, T. J., Carr, V. J., Taylor, R. L., \& ... Wilhelm, K. (2006). A randomized controlled trial of a smoking cessation intervention among people with a psychotic disorder. The American Journal of Psychiatry, 163, 1934-1942. doi:10.1176/appi.ajp.163.11.1934

Baldwin, S. A., Berkeljon, A., Atkins, D. C., Olsen, J. A., \& Nielsen, S. L. (2009). Rates of change in naturalistic psychotherapy: Contrasting dose-effect and good-enough level models of change. Journal of Consulting and Clinical Psychology, 77, 203-211. doi: $10.1037 / \mathrm{a} 0015235$

Bandura, A. (1997). Self-efficacy: The exercise of control, New York: Freeman.

Berrett, K. M. S. (2000). Youth Outcome Questionnaire (Y-OQ): Item sensitivity to change (Doctoral Dissertation, Brigham Young University, 2000). Dissertation Abstracts International, 60, 4876.

Boswell, J. F., Castonguay, L. G., \& Wasserman, R. H. (2010). Effects of psychotherapy training and intervention use on session outcome. Journal of Consulting and Clinical Psychology, 78, 717-723. doi:10.1037/a0020088 
Botella, L. \& Beriain, D. (2010). Allegiance effects in psychotherapy research: A constructivist approach. European Journal of Psychotherapy and Counselling 12, 55-64.

Breda, C. S., \& Heflinger, C. A. (2007). The impact of motivation to change on substance use among adolescents in treatment. Journal of Child \& Adolescent Substance Abuse, 16, 109-124. doi: 10.1300/J029v16n03_06

Britton, P. C., Williams, G. C., \& Conner, K. R. (2008). Self-determination theory, motivational interviewing, and the treatment of clients with acute suicidal ideation. Journal of Clinical Psychology, 64, 52-66.

Brogan, M. M., Prochaska, J. O., \& Prochaska, J. M. (1999). Predicting termination and continuation status in psychotherapy using the transtheroretical model. Psychotherapy, $36,105-113$.

Burlingame, G. M., Mosier, J. I., Wells, M. G., Atkin, Q. G., Lambert, M. J., Whoolery, M., .. . Latkowski, M. (2001). Tracking the influence of mental health treatment: The development of the Youth Outcome Questionnaire. Clinical Psychology and Psychotherapy, 8, 315-334.

Burlingame, G.M., Wells, M.G., Cox, J.C., Lambert, M.J., Latkowski, M., \& Ferre, R. (2005). Administration and scoring manual for the Y-OQ (Youth Outcome Questionnaire). Stevenson, MD: American Professional Credentialing Services.

Burlingame, G. M., Wells, M. G., Hoag, M., Hope, C., Nebeker, S., Konkel, K., et al. (1996). Administration and scoring manual for the Youth Outcome Questionnaire (Y-OQ.1). Stevenson, MD: American Professional Credentialing Services.

Burlingame, G. M., Wells, M. G., Lambert, M. J., Cox, J. C., \& Maruish, M. E. (2004). The Youth Outcome Questionnaire. In Maurish, M. (Ed.), The use of psychological testing for 
treatment planning and outcomes assessment (3rd ed.) (pp. 235-273). Mahwah, NJ US:

Lawrence Erlbaum Associates Publishers.

Cady, M. E., Winters, K. C., Jordan, D. A., Solberg, K. B., \& Stinchfield, R. D. (1996).

Motivation to change as a predictor of treatment outcome for adolescent substance abusers. Journal of Child and Adolescent Substance Abuse, 5, 73-91.

Cannon, J. A., Warren J. S., Nelson, P. L., Burlingame, G. M. (2010). Change trajectories for the Youth Outcome Questionnaire Self-Report: Identifying youth at risk for treatment failure. Journal of Clinical Child Adolescent Psychology, 39, 289-301.

Colby, S. M., Monti, P. M., Barnett, N. P., Rohsenow, D. J., Weissman, K., Spirito, A., \& ... Lewander, W. J. (1998). Brief motivational interviewing in a hospital setting for adolescent smoking: A preliminary study. Journal of Consulting and Clinical Psychology, 66, 574-578. doi:10.1037/0022-006X.66.3.574

Deci, E. L., Ryan, R. M. (1985). Intrinsic motivation and self-determination in human behavior. New York: Plenum.

Deci, E. L. \& Ryan, R. M. (1987). The support of autonomy and the control of behavior. Journal of Personality \& Social Psychology, 53, 1024-1037.

Deci, E. L., \& Ryan, R. M. (1991). A motivational approach to self: Integration in personality. In R. Dienstbier (Ed.), Nebraska Symposium on Motivation, 1990: Perspectives on motivation (pp. 237-288). Lincoln, NE US: University of Nebraska Press.

DiClemente, C. C., Bellino, L. E., \& Neavins, T. M. (1999). Motivation for change and alcoholism treatment. Alcohol Research \& Health, 23, 86-92.

DiClemente, C. C., Prochaska, J. O., Fairhurst, S. K., Velicer, W. F., Velasquez, M. M., \& Rossi, J. S. (1991). The process of smoking cessation: An analysis of precontemplation, 
contemplation, and preparation stages of change. Journal of Consulting and Clinical Psychology, 59, 295-304. doi:10.1037/0022-006X.59.2.295

Dozois, D. J. A., Westra, H. A., Collins, K. A., Fung, T. S., \& Garry, J. K. F. (2004). Stages of change in anxiety: Psychometric properties of the University of Rhode Island Change Assessment (URICA) scale. Behaviour Research and Therapy, 42, 711-729.

Dunn, C., DeRoo, L., \& Rivara, F. P. (2001). The use of brief interventions adapted from motivational interviewing across behavioral domains: A systematic review. Addiction, 96, 1725-1742. doi: 10.1080/09652140120089481

Etter, J.-F., \& Sutton, S. (2002). Assessing 'stage of change' in current and former smokers. Addiction, 97, 1171-1182. doi: 10.1046/j.1360-0443.2002.00198.x

Faul, F., Erdfelder, E., Buchner, A., \& Lang, A.-G. (2009). Statistical power analyses using G*Power 3.1: Tests for correlation and regression analyses. Behavior Research Methods, $41,1149-1160$.

Festinger, L. (1957). A theory of cognitive dissonance. Stanford, CA: Stanford University Press.

Field, C. A., Adinoff, B., Harris, T. R., Ball, S. A., \& Carroll, K. M. (2009). Construct, concurrent and predictive validity of the URICA: Data from two multi-site clinical trials. Drug and Alcohol Dependence, 101, 115-123.

Fowles, D. C. (1994). A motivational theory of psychopathology. In W. Spaulding (Ed.), Integrative views of motivation, cognition, and emotion. (pp. 181-238). Lincoln, NE US: University of Nebraska Press.

Friedman, A. S., Granick, S., \& Kreisher, C. (1994). Motivation of adolescent drug abusers for help and treatment. Journal of Child \& Adolescent Substance Abuse, 3, 69-88. doi: 10.1300/J029v03n01_07 
Garcia, J., \& Weisz, J. R. (2002). When youth mental health care stops: Therapeutic relationship problems and other reasons for ending youth outpatient treatment. Journal of Consulting and Clinical Psychology, 70, 439-443. doi:10.1037/0022-006X.70.2.439

Garland, A. F., Hurlburt, M. S., \& Hawley, K. M. (2006). Examining psychotherapy processes in a services research context. Clinical Psychology: Science and Practice, 13, 30-46. doi:10.1111/j.1468-2850.2006.00004.x

Geller, J., Brown, K. E., Zaitsoff, S. L., Menna, R., Bates, M. E., \& Dunn, E. C. (2008). Assessing readiness for change in adolescents with eating disorders. Psychological Assessment, 20, 63-69. doi: 10.1037/1040-3590.20.1.63

Greenstein, D. K., Franklin, M. E., \& McGuffin, P. (1999). Measuring motivation to change: An examination of the University of Rhode Island Change Assessment Questionnaire (URICA) in an adolescent sample. Psychotherapy: Theory, Research, Practice, Training, $36,47-55$.

Gusella, J., Butler, G., Nichols, L., Bird, D. (2003). A brief questionnaire to assess readiness to change in adolescents with eating disorders: Its application to group therapy. European Eating Disorders Review, 11, 58-71.

Haas, E., Hill, R. D., Lambert, M. J., \& Morrell, B. (2002). Do early responders to psychotherapy maintain treatment gains? Journal of Clinical Psychology, 58, 1157-1172. Hasler G., Klaghofer R., \& Buddeberg C. (2003). The University of Rhode Island Change Assessment Scale (URICA). Psychotherapie, Psychosomatik, Medizineische Psychologie, 53, 406-411. 
Hayes, A. M., Laurenceau, J-P, Feldman, G. C., Strauss, J. L., \& Cardaciotto, L.A. (2007). Change is not always linear: The study of nonlinear and discontinuous patterns of change in psychotherapy. Clinical Psychology Review, 27, 715-724.

Henderson, M. J., Saules, K. K., \& Galen, L. W. (2004). The predictive validity of the University of Rhode Island Change Assessment Questionnaire in a heroin-addicted polysubstance abuse sample. Psychology of Addictive Behaviors, 18, 106-112. doi: 10.1037/0893164x.18.2.106

Hettema, J., Steele, J., \& Miller, W. R. (2005). Motivational Interviewing. Annual Review of Clinical Psychology, 1, 91-111. doi:10.1146/annurev.clinpsy.1.102803.143833

Holt, W. E. (1967). The concept of motivation for treatment. The American Journal of Psychiatry, 123, 1388-1394.

Hull, C. (1943). Principles of behavior. New York: Appleton-Century-Crofts.

Jainchill, N., Bhattacharya, G., \& Yagelka, J. (1995). Therapeutic communities for adolescents. In D. Rahdert, \& D. Cechowicz (Eds.), Adolescent drug abuse: Clinical assessment and therapeutic interventions (pp. 190-217). Research monograph series, Vol. 156.

Rockville, MD: National Institute on Drug Abuse.

Joe, G. W., Simpson, D. D., \& Broome, K. M. (1998). Effects of readiness for drug abuse treatment on client retention and assessment of process. Addiction, 93, 1177-1190. doi: $10.1080 / 09652149835008$

Kazdin, A. E. (1991) Effectiveness of psychotherapy with children and adolescents. Journal of Consulting and Clinical Psychology, 59, 785-798.

Kazdin, A. E. (1995). Child, parent and family dysfunction as predictors of outcome in cognitivebehavioral treatment of antisocial children. Behavior Research and Therapy, 33, 271-281. 
Kazdin, A. E. (1995). Bridging child, adolescent and adult psychotherapy: Directions for research, Psychotherapy Research, 5, pp 258-277.

Kazdin, A. E. (1996). Dropping out of child therapy: Issues for research and implications for practice. Clinical Child Psychology and Psychiatry, 1, 133-156.

Kazdin, A. E. (2003). Psychotherapy for children and adolescents. Annual Review of Psychology, $54,253-276$.

Kazdin, A. E. (2004). Psychotherapy for children and adolescents. In M. Lambert (Ed.), Bergin and Garfield's handbook of psychotherapy and behavior change. (5th ed.) (pp.543-589). New York: John Wiley \& Sons, Inc.

Kazdin, A.E. (2007). Mediators and mechanisms of change in psychotherapy research. In S. Nolen- Hoeksema, T. Cannon, \& T. Widiger (Eds.), Annual Review of Clinical Psychology, 3, 1-27.

Kazdin, A.E. (2008). Evidence-based treatment and practice: new opportunities to bridge clinical research and practice, enhance the knowledge base, and improve patient care. American Psychologist, 63, 146-159.

Kazdin, A. E. (2009). Understanding how and why psychotherapy leads to change. Psychotherapy Research, 19, 419-428.

Kazdin, A. E., Bass, D., Ayers, W. A., \& Rodgers, A. (1990). Empirical and clinical focus of child and adolescent psychotherapy research. Journal of Consulting and Clinical Psychology, 58, 729-740.

Kazdin, A. E., \& Blase, S. L. (2011). Rebooting psychotherapy research and practice to reduce the burden of mental illness. Perspectives on Psychological Science, 6, 21-37. doi:10.1177/1745691610393527 
Kazdin, A. E., Mazurick, J. L., \& Siegel, T. C. (1994). Treatment outcome among children with externalizing disorder who terminate prematurely versus those who complete psychotherapy. Journal of the American Academy of Child \& Adolescent Psychiatry, 33, 549-557. doi:10.1097/00004583-199405000-00013

Kazdin, A. E. \& Nock, M. K. (2003). Delineating mechanisms of change in child and adolescent therapy: Methodological issues and research recommendations. Journal of Child Psychology and Psychiatry 44, 1116-1129.

Kazdin, A. E., \& Wassell, G. (2000). Therapeutic changes in children, parents, and families resulting from treatment of children with conduct problems. Journal of the American Academy of Child \& Adolescent Psychiatry, 39, 414-420. doi:10.1097/00004583200004000-00009

Killeen, P. R. (1985). Incentive theory: IV. Magnitude of reward. Journal of the Experimental Analysis of Behavior, 43, 407-417. doi: 10.1901/jeab.1985.43-407

King, K. M., Chung, T., \& Maisto, S. A. (2009). Adolescents' thoughts about abstinence curb the return of marijuana use during and after treatment. Journal of Consulting and Clinical Psychology, 77, 554-565.

Krug, S. E., \& Henry, T. J. (1974). Personality, motivation, and adolescent drug use patterns. Journal of Counseling Psychology, 21, 440-445. doi: 10.1037/h0037022

Kuchipudi, V. V., Hobein, K. K., Flickinger, A. A., \& Iber, F. L. (1990). Failure of a 2-hour motivational intervention to alter recurrent drinking behavior in alcoholics with gastrointestinal disease. Journal of Studies on Alcohol, 51, 356-360. 
Lambert, M. J. (1999). Are differential treatment effects inflated by researcher therapy allegiance? Could Clever Hans count? Clinical Psychology: Science and Practice, 6, $127-130$.

Lambert, M. J., \& Ogles, B. M. (2004). The efficacy and effectiveness of psychotherapy. In M. Lambert (Ed.), Bergin \& Garfield's Handbook of psychotherapy and behavior change (5 ${ }^{\text {th }}$ ed.) (pp. 139-193). New York: Wiley.

Lambie, G. W., \& Sias, S. (2006). Motivation Enhancement Therapy: An effective approach for counseling unmotivated adolescents. In G. R. Walz, J. C. Bleuer \& R. K. Yep (Eds.), Vistas: Compelling perspectives on counseling 2006 (pp. 37-41). Alexandria, VA US: American Counseling Association.

Laurenceau, J. P., Hayes, A. M., \& Feldman, G. C. (2007). Some methodological and statistical issues in the study of change processes in psychotherapy. Clinical Psychology Review, 27, 682-695.

Lennox, R., \& Cecchini, M. (2008). The NARCONON drug education curriculum for high school students: A non-randomized, controlled prevention trial. Substance Abuse Treatment, Prevention, and Policy, 3, 8 .

Levant, R. F., \& Hasan, N. T. (2008). Evidence-based practice in psychology. Professional Psychology: Research and Practice, 39, 658-662.

Lilienfeld, S. O. (2007). Psychological treatments that cause harm. Perspectives on Psychological Science, 2, 53-70. doi:10.1111/j.1745-6916.2007.00029.x

Little, R. J. A. (1988). A test of missing completely at random for multivariate data with missing values. Journal of the American Statistical Association, 83, 1198-1202. 
Little, R. J. A. \& Rubin, D. B. (2002). Statistical analysis with missing data. (2 ${ }^{\text {nd }}$ ed.). New York: John Wiley.

Lutz, W. (2003). Efficacy, effectiveness, and expected treatment response in psychotherapy. Journal of Clinical Psychology, 59, 745-750.

Madson, M. B., \& Campbell, T. C. (2006). Measures of fidelity in motivational enhancement: A systematic review of instrumentation. Journal of Substance Abuse Treatment, 31, 67-73.

Markland, D., Ryan, R. M., Tobin, V. J., \& Rollnick, S. (2005). Motivational Interviewing and Self-Determination Theory. Journal of Social \& Clinical Psychology, 24, 811-831.

Mash, E. J., \& Dozois, D. A. (2003). Child psychopathology: A developmental-systems perspective. In E. Mash, \& R. Barkley (Eds.), Child psychopathology (2nd ed.) (pp. 371). New York, NY US: Guilford Press.

Masyn, K. E. (2006). A review of applied longitudinal data analysis: Modeling change and event occurrence. Journal of Educational and Behavioral Statistics, 31, 353-356. doi: $10.3102 / 10769986031003353$

McClellan, J. M., \& Werry, J. (2003). Evidence-based treatments in child and adolescent psychiatry: An inventory. Journal of the American Academy of Child \& Adolescent Psychiatry, 42, 1388-1400. doi:10.1097/00004583-200312000-00005

McClendon, D. T., Warren, J. S., Green, K. M., Burlingame, G. M., Eggett, D. L., McClendon, R. J., (2011). Sensitivity to change of youth treatment outcome measures: A comparison of the CBCL, BASC-2, and Y-OQ. Journal of Clinical Psychology, 67, 111-125.

McConnaughy, E. A., DiClemente, C. C., Prochaska, J. O., \& Velicer, W. F. (1989). Stages of change in psychotherapy: A follow-up report. Psychotherapy: Theory, Research, Practice, Training, 26, 494-503. 
McConnaughy, E. A., Prochaska, J. O., \& Velicer, W. F. (1983). Stages of change in psychotherapy: Measurement and sample profiles. Psychotherapy: Theory, Research \& Practice, 20, 368-375.

McCuller, W. J., Sussman, S., Wapner, M., Dent, C., \& Weiss, D. J. (2006). Motivation to quit as a mediator of tobacco cessation among at-risk youth. Addictive Behaviors, 31, 880888.

McLachlan, G., \& Peel, D. (2000). Finite mixture models. New York: John Wiley.

Melnick, G., De Leon, G., Hawke, J., Jainchill, N., \& Kressel, D. (1997). Motivation and readiness for therapeutic community treatment among adolescents and adult substance abusers. American Journal of Drug and Alcohol Abuse, 20, 485-507.

Miller, W. R. \& Rollnick, S. (2002). Motivational Interviewing: Preparing people for change ( $2^{\text {nd }}$ ed.). New York: Guilford Press.

Miller, W. R., \& Rose, G. S. (2009). Toward a theory of motivational interviewing. American Psychologist, 64, 527-537.

Miller, W. R., Yahne, C. E., \& Tonigan, J. S. (2003). Motivational Interviewing in drug abuse services: A randomized trial. Journal of Consulting and Clinical Psychology, 71, $754-763$.

Mosier, J. I. (1998). The predictive validity of the Youth Outcome Questionnaire: Prognostic assessment. University of Utah, Salt Lake City.

Muthén, B. \& Asparouhov, T. (2009). Growth mixture modeling: Analysis with non-Gaussian random effects. In G. Fitzmaurice, M. Davidian, G. Verbeke, \& G. Molenberghs (Eds.), Longitudinal data analysis (pp. 143-165). Boca Raton: Chapman \& Hall/CRC Press. 
Muthén, B. \& Shedden, K. (1999). Finite mixture modeling with mixture outcomes using the EM algorithm. Biometrics, 55, 463-469.

Muthén, L. K., \& Muthén, B. O. (1998-2011). Mplus user's guide. (6 ${ }^{\text {th }}$ ed.). Los Angeles, CA: Muthén \& Muthén.

Nathan, P. E. (2002). Efficacy, effectiveness, and the clinical utility of psychotherapy research. In P. Nathan \& J. Gorman (Eds.), A guide to treatments that work (2nd ed.) (pp. 642654). New York, NY US: Oxford University Press.

Ondersma, S. J., Winhusen, T., Erickson, S. J., Stine, S. M., \& Wang, Y. (2009). Motivation enhancement therapy with pregnant substance-abusing women: Does baseline motivation moderate efficacy? Drug and Alcohol Dependence, 101, 74-79. doi:10.1016/j.drugalcdep.2008.11.004

Pantalon, M. V., Nich, C., Franckforter, T., \& Carroll, K. M. (2002). The URICA as a measure of motivation to change among treatment-seeking individuals with concurrent alcohol and cocaine problems. Psychology of Addictive Behaviors, 16, 299-307. doi:10.1037/0893-164X.16.4.299

Perkins, S., Schmidt, U., Eisler, I., Treasure, J., Berelowitz, M., Dodge, E., . . Yi, 1. (2007). Motivation to change in recent onset and long-standing bulimia nervosa: Are there differences? Eating and Weight Disorders, 12, 61-69.

Pina, A. A., Silverman, W. K., Weems, C. F., Kurtines, W. M., \& Goldman, M. L. (2003). A comparison of completers and noncompleters of exposure-based cognitive and behavioral treatment for phobic and anxiety disorders in youth. Journal of Consulting and Clinical Psychology, 71, 701-705. doi:10.1037/0022-006X.71.4.701 
Pinto, A., Pinto, A. M., Neziroglu, F., \& Yaryura-Tobias, J. A. (2007). Motivation to change as a predictor of treatment response in obsessive compulsive disorder. Annals of Clinical Psychiatry, 19, 83-87.

Prochaska, J. O., \& DiClemente, C. C. (1982). Transtheoretical therapy: Toward a more integrative model of change. Psychotherapy: Theory, Research \& Practice, 19, 276-288.

Prochaska, J.O. \& DiClemente, C. C. (2005). The transtheoretical approach. In J. Norcross \& M. Goldfried (Eds.), Handbook of psychotherapy integration (2nd ed.) (pp. 147-171). New York: Oxford University Press.

Prochaska, J. O., DiClemente, C.C., \& Norcross, J.C. (1992). In search of how people change: Applications to addictive behaviors. American Psychologist, 47, 1102-1114.

Prochaska, J. O., DiClemente, C. C., Norcross, J. C., Marlatt, G. A., \& VandenBos, G. R. (1997). In search of how people change: Applications to addictive behaviors. Addictive behaviors: Readings on etiology, prevention, and treatment (pp. 671-696). Washington, DC US: American Psychological Association.

Prochaska, J. O., Norcross, J. C., Fowler, J., Follick, M. J., \& Abrams, D. B. (1992). Attendance and outcome in a worksite weight control program: Processes and stages of change as process and predictor variables. Addictive Behaviors, 17, 35-45.

Reiss, S. (2004). Multifaceted nature of intrinsic motivation: The theory of 16 basic desires. Review of General Psychology, 8, 179-193. doi:10.1037/1089-2680.8.3.179

Ridge, N.W., Warren, J.S., Burlingame, G.M., Wells, M.G., \& Tumblin, K.M. (2009). Reliability and validity of the Youth Outcome Questionnaire Self-Report. Journal of Clinical Psychology, 65, 1115-1126. 
Rieger, E., Touyz, S., Schotte, D., Beumont, P., Russell, J., Clarke, S. . . Griffiths, R. (2000). Development of an instrument to assess readiness to recover in anorexia nervosa. International Journal of Eating Disorders, 28, 387-396.

Rodríguez-Cano, T., \& Beato-Fernández, L. (2005). Attitudes towards change and treatment outcome in eating disorders. Eating and Weight Disorders, 10, 59-65.

Rollnick, S., Heather, N., Gold, R., \& Hall, W. (1992). Development of a short 'readiness to change' questionnaire for use in brief, opportunistic interventions among excessive drinkers. British Journal of Addiction, 87, 743-754.

Rosenbaum, R. L., \& Horowitz, M. J. (1983). Motivation for psychotherapy: A factorial and conceptual analysis. Psychotherapy: Theory, Research \& Practice, 20, 346-354. doi: $10.1037 / \mathrm{h} 0090205$

Rumpold, G., Doering, S., Smrekar, U., Schubert, C., Koza, R., Schatz, D. S., . . Schuessler, G. (2005). Changes in motivation and the therapeutic alliance during a pretherapy diagnostic and motivation-enhancing phase among psychotherapy outpatients. Psychotherapy Research, 15, 117-127.

Ryan, R. M., \& Deci, E. L. (2000). Self-determination theory and the facilitation of intrinsic motivation, social development, and well-being. American Psychologist, 55, 68-78. doi: 10.1037/0003-066x.55.1.68

Ryan, R. M., \& Deci, E. L. (2008). A self-determination theory approach to psychotherapy: The motivational basis for effective change. Canadian Psychology/Psychologie canadienne, 49, 186-193. 
Sainsbury, L., Krishnan, G., \& Evans, C. (2004). Motivating factors for male forensic patients with personality disorder. Criminal Behaviour and Mental Health, 14, 29-38. doi: $10.1002 / \mathrm{cbm} .558$

Singer, J. D., \& Willett, J. B. (2003). Applied longitudinal data analysis: Modeling change and event occurrence. New York, NY US: Oxford University Press.

Sutton, S. (2001). Back to the drawing board? A review of applications of the transtheoretical model to substance use. Addiction, 96, 175-186. doi: 10.1080/09652140120089508

U.S. Census Bureau (2010). Population finder: Utah. Retrieved March 29, 2013, from http://www.census.gov/2010census/popmap/ipmtext.php?fl=49

Vansteenkiste, M., \& Sheldon, K. M. (2006). There's nothing more practical than a good theory: Integrating motivational interviewing and self-determination theory. British Journal of Clinical Psychology, 45, 63-82.

Warren, J. S., Nelson, P. L., Mondragon, S. A., Baldwin, S. A., \& Burlingame, G. M. (2010). Youth psychotherapy change trajectories and outcomes in usual care: Community mental health versus managed care settings. Journal of Consulting and Clinical Psychology, 78, 144-155. doi:10.1037/a0018544

Warren, J. S., Packard, A. E., Ludwig, K. A., Mondragon, S. A., Smart, L., \& Sasser, T. (2008, October). Evaluating change processes in community-based mental health services. Paper presented at the Kansas Conference in Clinical Child and Adolescent Psychology, Lawrence, KS.

Weersing, V., \& Weisz, J. R. (2002). Community clinic treatment of depressed youth: Benchmarking usual care against CBT clinical trials. Journal of Consulting and Clinical Psychology, 70, 299-310. doi:10.1037/0022-006X.70.2.299 
Weisz, J. R. (2004). Psychotherapy for children and adolescents: Evidence-based treatments and case examples. Cambridge, United Kingdom: Cambridge University Press.

Weisz, J. R., Jensen, A. L., \& McLeod, B. D. (2005). Development and dissemination of child and adolescent psychotherapies: Milestones, methods, and a new deployment-focused model. In E. Hibbs \& P. Jensen (Eds.), Psychosocial treatments for child and adolescent disorders: Empirically based strategies for clinical practice ( $2^{\text {nd }}$ ed.) (pp. 9-39).

Washington, DC US: American Psychological Association.

Weisz, J. R. \& Kazdin, A. E. (2003). Concluding thoughts: present and future of evidence-based psychotherapies for children and adolescents. In A. E. Kazdin \& J. R. Weisz (Eds.), Evidence-based psychotherapies for children and adolescents (pp.439-451). New York: Guilford Press.

Weisz, J.R., Jensen-Doss, A., \& Hawley, K.M. (2006). Evidence-based youth psychotherapies versus usual clinical care: A meta-analysis of direct comparisons. American Psychologist, $61,671-689$.

Weisz, J. R., Moore, P. S., Southam-Gerow, M. A., Weersing, V. R., Valeri, S. M., \& McCarty, C. A. (1999). Therapist manual: Primary and secondary control enhancement training program (2 $2^{\text {nd }}$ ed.). Los Angeles: University of California.

Weisz, J. R., Weiss, B., \& Donenberg, G. R. (1992). The lab versus the clinic: Effects of child and adolescent psychotherapy. American Psychologist, 47, 1578-1585.

Weisz, J. R., Weiss, B., Han, S. S., Granger, D. A., \& Morton, T. (1995). Effects of psychotherapy with children and adolescents revisited: A meta-analysis of treatment outcome studies. Psychological Bulletin, 117, 450-468. 
Wells, M. G., Burlingame, G. M., Lambert, M. J., Hoag, M. J., \& Hope, C. A. (1996).

Conceptualization and measurement of patient change during psychotherapy:

Development of the Outcome Questionnaire and Youth Outcome Questionnaire.

Psychotherapy: Theory, Research, Practice, Training, 33, 275-283.

West, R. (2005). Time for a change: putting the Transtheoretical (Stages of Change) Model to rest. Addiction, 100, 1036-1039.

Whitelaw, S., Baldwin, S., Bunton, R., \& Flynn, D. (2000). The status of evidence and outcomes in stages of change research. Health Education Research, 15, 707-718. doi:10.1093/her/15.6.707

Wierzbicki, M. \& Pekarik, G. (1993). A meta-analysis of psychotherapy dropout. Professional Psychology: Research and Practice, 24, 190-195. doi:10.1037/0735-7028.24.2.190

Wilson, G. T., \& Schlam, T. R. (2004). The transtheoretical model and motivational interviewing in the treatment of eating and weight disorders. Clinical Psychology Review, 24, 361-378. doi: $10.1016 /$ j.cpr.2004.03.003

Winhusen, T., Kropp, F., Babcock, D., Hague, D., Erickson, S. J., Renz, C., \& ... Somoza, E. (2008). Motivational enhancement therapy to improve treatment utilization and outcome in pregnant substance users. Journal of Substance Abuse Treatment, 35, 161-173. doi:10.1016/j.jsat.2007.09.006

Wulfert, E., Blanchard, E. B., \& Martell, R. (2003). Conceptualizing and treating pathological gambling: A motivationally enhanced cognitive behavioral approach. Cognitive and Behavioral Practice, 10, 61-72. doi: 10.1016/s1077-7229(03)80009-3

Yang, C. (2006). Evaluating latent class analyses in qualitative phenotype identification. Computational Statistics \& Data Analysis, 50, 1090-1104. 
Zaitsoff, S. L., \& Taylor, A. (2009). Factors related to motivation for change in adolescents with eating disorders. European Eating Disorders Review, 17, 227-233.

Zuroff, D. C., Koestner, R., Moskowitz, D. S., McBride, C., Marshall, M., \& Bagby, M. (2007). Autonomous motivation for therapy: A new common factor in brief treatments for depression. Psychotherapy Research, 17, 137-147. 


\section{Appendix}

\section{TSM - YOUTH}

Today's Date:

ID \#:

Your Age:

Male $\circ$ Female $\circ$ Your Race/Ethnicity:

INSTRUCTIONS (\#1-15): Please rate how confident you are that you can do each of the things described below. Circle the answer that best describes how you have felt about these things over the past week.

1) I can make and keep good friends.

$\begin{array}{cc}\text { Strongly } & \text { Slightly } \\ \text { Disagree } & \text { Disagree }\end{array}$ Neutral $\begin{gathered}\text { Slightly } \\ \text { Agree }\end{gathered} \begin{gathered}\text { Strongly } \\ \text { Agree }\end{gathered}$

2) I can get along well with most people.

3) When I have problems with friends, I can work things out.

4) I can work well in a group.

5) I can achieve my goals in life.

6) I can live up to what my parents expect of me.

7) I can live up to what I expect of myself.

8) I can control my temper.

9) When I have a problem, I can find ways to solve it.

10) If I make a mistake, I can fix it.

11) When there are problems in my family, I can do things to improve the situation.

$\begin{array}{lllll}1 & 2 & 3 & 4 & 5 \\ 1 & 2 & 3 & 4 & 5 \\ 1 & 2 & 3 & 4 & 5 \\ 1 & 2 & 3 & 4 & 5 \\ 1 & 2 & 3 & 4 & 5 \\ 1 & 2 & 3 & 4 & 5 \\ 1 & 2 & 3 & 4 & 5 \\ 1 & 2 & 3 & 4 & 5 \\ 1 & 2 & 3 & 4 & 5 \\ 1 & 2 & 3 & 4 & 5 \\ 1 & 2 & 3 & 4 & 5 \\ 1 & 2 & 3 & 4 & 5 \\ 1 & 2 & 3 & 4 & 5 \\ 1 & 2 & 3 & 4 & 5 \\ 1 & 2 & 3 & 4 & 5\end{array}$

15) I can motivate myself to do schoolwork. $\quad \begin{array}{llllll}5 & 1 & 2 & 3 & 4 & 5\end{array}$

INSTRUCTIONS (\#16-30): These questions are about your relationships with your immediate family (e.g., father, mother, step-parent or guardian, brother, sister), your extended family (grandparents, aunts, uncles, cousins) and your friends. Circle the answer that best describes how you have felt about these things over the past week.

16) I have an immediate family member (father, mother, brother, or sister) who I can turn to for good advice.

17) I feel like I "fit in" and belong with the members of my immediate family.

18) My immediate family appreciates my abilities and helps me to believe in myself.

$\begin{array}{ccccc}1 & 2 & 3 & 4 & 5 \\ 1 & 2 & 3 & 4 & 5 \\ 1 & 2 & 3 & 4 & 5 \\ \begin{array}{c}\text { Strongly } \\ \text { Disagree }\end{array} & \begin{array}{c}\text { Slightly } \\ \text { Disagree }\end{array} & \text { Neutral } & \begin{array}{c}\text { Slightly } \\ \text { Agree }\end{array} & \begin{array}{c}\text { Strongly } \\ \text { Agree }\end{array}\end{array}$




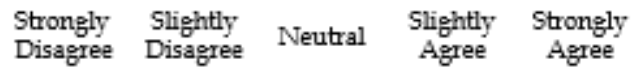

19) I feel like my immediate family needs me.

20) I feel emotionally connected to the members of my immediate family (we care about each other).

21) I have an extended family member (grandparent, uncle, aunt, or cousin) who I can turn to for good advice.

22) I can count on members of my extended family if I need help.

23) My extended family appreciates my abilities and helps me to believe in myself.

24) I feel like my extended family needs me.

25) I feel emotionally connected to the members of my extended family (we care about each other).

26) I have family members or friends who can help me in material ways, like providing me with food, clothing, or money.

27) I feel like I "fit in" and belong with friends my age.

28) I have a friend who I can turn to for good advice.

29) My friends appreciate my abilities and help me to believe in myself.

$\begin{array}{lllll}1 & 2 & 3 & 4 & 5 \\ 1 & 2 & 3 & 4 & 5 \\ 1 & 2 & 3 & 4 & 5 \\ 1 & 2 & 3 & 4 & 5 \\ 1 & 2 & 3 & 4 & 5 \\ 1 & 2 & 3 & 4 & 5 \\ 1 & 2 & 3 & 4 & 5 \\ 1 & 2 & 3 & 4 & 5 \\ 1 & 2 & 3 & 4 & 5 \\ 1 & 2 & 3 & 4 & 5 \\ 1 & 2 & 3 & 4 & 5 \\ 1 & 2 & 3 & 4 & 5\end{array}$

30) I feel emotionally connected to at least one friend my age (we
care about each other).

INSTRUCTIONS (\#31-35): These questions ask how you feel about being in therapy. Circle the answer that best describes how you have felt about these things over the past week.

\begin{tabular}{|c|c|c|c|c|}
\hline 31) I'm glad I'm coming to therapy. & 1 & 2 & 3 & 4 \\
\hline 32) The things I work on in therapy will help me in the future. & 1 & 2 & 3 & 4 \\
\hline 33) Coming to therapy is a waste of time for me. & 1 & 2 & 3 & \\
\hline $\begin{array}{l}\text { 34) I'm only in therapy because my parent (or someone else) thinks } \\
\text { I need help. }\end{array}$ & 1 & 2 & 3 & \\
\hline 35) I am willing to do my part in therapy to make things better. & 1 & 2 & 3 & \\
\hline 36) I'm not going to change the way I am by coming to therapy. & 1 & 2 & 3 & 4 \\
\hline 37) I'm coming to therapy to get the help I need. & 1 & 2 & 3 & 4 \\
\hline
\end{tabular}

INSTRUCTIONS (\#36-40): These questions are about working with your therapist. Circle the answer that best describes how you have felt about these things over the past week. It's ok to say how you really feel about these things your honest answers will help ensure you receive the services you need.

38) I feel like my therapist is on my side and tries to help me.

39) I look forward to meeting with my therapist.

40) I don't feel I'm making much progress with my therapist.

41) I feel like my therapist knows how to help me.

42) My therapist really listens to me.

\begin{tabular}{|c|c|c|c|c|}
\hline 1 & 2 & 3 & 4 & 5 \\
\hline 1 & 2 & 3 & 4 & 5 \\
\hline 1 & 2 & 3 & 4 & 5 \\
\hline 1 & 2 & 3 & 4 & 5 \\
\hline 1 & 2 & 3 & 4 & 5 \\
\hline $\begin{array}{l}\text { Strongly } \\
\text { Disagree }\end{array}$ & $\begin{array}{l}\text { Slightly } \\
\text { Disagree }\end{array}$ & Neutral & $\begin{array}{l}\text { Slightly } \\
\text { Agree }\end{array}$ & $\begin{array}{c}\text { Strongly } \\
\text { Agree }\end{array}$ \\
\hline
\end{tabular}


name is , and I am part of a research team from Brigham Young University. We are trying to learn more about the things that help children and youth benefit from counseling services. Because you are receiving services through Wasatch Mental Health, we are inviting you to participate in this study, and would like to give $\$ 10$ to each participating parent and child today for helping us. Participating is simple; parents complete these two questionnaires [hold up forms] plus one that is already part of your regular paperwork today. The three forms will take about 20-30 minutes to finish. Also, for youth ages 10-17 there are two questionnaires, this one [hold up TSM-Y] and one you would fill out anyway as part of your appointment today. These forms ask questions about your thoughts, feelings, and behaviors, and may help your therapist and others that work with you have a better idea about how to help your family.

Because we want to learn how your thoughts, feelings and behaviors may change over the course of treatment, we will ask you to complete the two shorter forms before each of your next four visits, then once every few weeks after that. Each time it would take about 10-15 minutes to complete the two forms (but, one of these you would be asked to fill out each time anyway as part of your services here). So, you would need to come about 10-15 minutes early on those days to complete the forms.

Besides giving each participating parent and child $\$ 10$ today for helping us, we would like to give each of you another $\$ 10$ for completing the forms at your $5^{\text {th }}$ appointment, making a total of $\$ 40$ per family. Also, families who continue in the study for 6 months or until the end of treatment (whichever comes first) will be entered in a drawing to receive a cash prize of $\$ 100$ (we have $10 \$ 100$ prizes to give away). Finally, every time you complete the forms, including today, kids and youth participants can pick a prize from this treasure chest of prizes [show chest and prize samples].

This study is for parents who have children between the ages of 4 and 17 who are receiving services, and for youth ages 10-17. Your answers on the questionnaires will be confidential, meaning only authorized research and treatment personnel will be able to see them. Also, you can decide not to participate and it won't impact the regular services you would receive here. So, thanks for taking the time to listen and to consider participating. Do you have any questions?

Thank you!

\section{Consent to be a Research Subject Parental Consent Form (clinical)}

Introduction: This research study is being conducted by Jared Warren, Ph.D., at Brigham Young University, in collaboration with this treatment facility, to learn more about factors related to youth mental health outcomes. This research will be used to help plan and evaluate the mental health treatment received by children and adolescents. You are being invited because your child is currently receiving services at this treatment facility. 
Procedures: Each parent/guardian will be asked to complete 3 questionnaires at the first visit to this facility. Youth who are age 10 and above are also invited to participate by completing 3 similar questionnaires. For parents and youth, the questionnaires will take 20-30 minutes to complete. Parents/guardians will complete questionnaires about their child's behavioral and emotional functioning; their own attitudes, feelings and approaches toward parenting; their supportive relationships with others; their own behaviors and moods; and their thoughts about working with the child's therapist. Youth participants will complete questionnaires about their relationships with others; their behaviors, attitudes, moods; and their thoughts about therapy. To learn about how these areas may change or stay the same over time, you (and your child if age 10 and above) will be asked to complete two of the same questionnaires at each of the first five sessions, and approximately every 3 weeks after that (each requiring 10 to 15 minutes for both parents and youth). Your participation in the study would conclude after 6 months or when you complete treatment, whichever comes first.

Risks/Discomforts: The risks for participating in this study are minimal. However, you may feel emotional discomfort when answering questions about your thoughts and behaviors, and your approaches to parenting.

Benefits: You and your child may benefit directly from participating in this study, as a summary of the results of the questionnaires will be made available to your child's treatment team, possibly improving the process of psychological assessment, treatment planning, and service delivery. At a more general level, it is hoped that through your participation, researchers will learn more about parent and child characteristics that can be used to improve the response of children and adolescents to therapy.

Confidentiality: All information provided will remain confidential and only the study research staff and authorized treatment providers at this facility will have access to this information. A study ID number will be assigned to each participant, and names will not be included in the study database. Completed questionnaires will be maintained in locked filing cabinets in a secure research lab at Brigham Young University until the data have been transferred to the anonymous database, after which the questionnaires will be shredded. Only the study coordinators will be able to link study ID's with names of participants, and study results will be reported as a group so that individuals cannot be identified by their responses. To assist the child's progress in therapy, a summary of the results will included in his/her case file at this facility.

Compensation: The participating parent and the identified child/adolescent will each receive $\$ 10$ at the first session, and each will receive an additional $\$ 10$ for completing forms at the $5^{\text {th }}$ session (total of $\$ 40$ per participating family). In addition, participant families who remain in the study until the end of treatment or for 6 months (whichever comes first), will be entered in a drawing to receive a cash prize of $\$ 100$ (10 such prizes will be awarded). Finally, for every session at which forms are completed, child and youth participants can pick a small prize from a "treasure chest" of prizes.

Participation: Participation in this research study is voluntary. You have the right to withdraw at any time or refuse to participate entirely without jeopardy to the services received at this mental health care facility.

Questions about the Research: If you have questions regarding this study, you may contact Jared Warren, Ph.D., at (801) 422-5600, 291 TLRB, Provo, UT 84602, or by email at jared_warren@byu.edu.

Questions about your Rights as Research Participants: If you have questions regarding your rights as a research participant, you may contact If you have questions regarding your rights as a research 
participant, you may contact BYU IRB Administrator, Brigham Young University, A-285 ASB, Provo, UT 84602,801-422-1461,irb@byu.edu.

I have read, understood, and received a copy of the above consent and desire or my own free will to participate in this study.

Signature of Parent/Guardian:

Date:

Please print your Child's name:

Please print your name:

Mailing address:

Phone number:

\section{Research Study}

Youth Assent

(clinical)

You are invited to participate in a research study with your parent or guardian. The reason we are doing this study is to learn more about things that may help youth get better from therapy. If you would like to participate, we expect you to complete some questionnaires that will take 20 to 30 minutes to complete. The questions will be about your relationships with others, things you feel you can do, and your thoughts about therapy. You can expect us to keep your answers private. Your answers will be given to your therapists so they can help you during your time in therapy. Your parent or guardian will not see your answers unless you would like to share them. We will keep your completed questionnaires in a locked filing cabinet at Brigham Young University.

To thank you for your participation, you will be given $\$ 10$ today, and another $\$ 10$ in a few weeks for continuing to complete the questionnaires when you come in.

Your participation in this study is voluntary, and you can stop participating at any time. If you choose to stop participating, this will not impact your therapy. If you would like to participate in this research study please sign your name below.

Signature of Youth Participant:

Date:

Witness:

(person besides parent or primary investigator of the study)

Questions about the Research: If you have questions regarding this study, you may contact Jared Warren, Ph.D., at (801) 422-5600, 291 TLRB, Provo, UT 84602, or by email at jared_warren@byu.edu.

Questions about your Rights as Research Participants: If you have questions regarding your rights as a research participant, you may contact BYU IRB Administrator, Brigham Young University, A-285 ASB, Provo, UT 84602, 801-422-1461, irb@,byu.edu. 